\title{
Effects of lateral mixing on the mean state and eddy activity of an equatorial ocean
}

\section{P. Pezzi ${ }^{1}$}

School of Ocean and Earth Science (SOES), University of Southampton, Southampton Oceanography Centre (SOC), Southampton, UK

\section{K. J. Richards}

International Pacific Research Center/SOEST, University of Hawaii at Manoa, Honolulu, Hawaii, USA

Received 24 February 2003; revised 24 August 2003; accepted 3 October 2003; published 2 December 2003.

[1] Numerical experiments are performed using an ocean general circulation model (OGCM) to assess the impact of the form of lateral mixing of momentum and tracers on the state of an equatorial ocean. It is found that the large-scale structure of both the velocity and temperature fields are very sensitive to the imposed parameterization of lateral mixing in the model. With uniform values for the viscosity and diffusion coefficient across the domain, a decrease in these coefficients increases the activity of tropical instability waves (TIW), resulting in an increase in the sea surface temperature of the cold tongue, and thus overcoming the cold bias often found in ocean models of the equatorial Pacific. However, there is an associated increase in the strength of the Equatorial Under-Current (EUC) to unrealistic levels. It is found that the strength of the EUC can be limited, while little affecting the TIW activity, by applying an enhanced level of mixing in the vicinity of the equator. This enhanced mixing is used to model the effect of the observed interleaving of water masses across the equator. Both the level and distribution of eddy kinetic energy (associated with TIWs) varies with the level and orientation of the lateral mixing. An examination of the main energy conversion terms of mean to eddy energy reveals that both the barotropic and baroclinic energy conversion terms are important for the production of TIWs. The relative role of each of these conversion terms changes as the lateral mixing is decreased. At low levels of lateral mixing, barotropic instability is found to dominate the production of total eddy energy. Including enhanced mixing at the equator decreases this barotropic production, but surprisingly increases the baroclinic production away from the equator. INDEX TERMS: 4231 Oceanography: General: Equatorial oceanography; 4520 Oceanography: Physical: Eddies and mesoscale processes; 4532 Oceanography: Physical: General circulation; 4568 Oceanography: Physical: Turbulence, diffusion, and mixing processes; KEYWORDS: lateral mixing, mixing orientation, enhanced equatorial mixing, tropical instability waves (TIWs), equatorial Pacific dynamics

Citation: Pezzi, L. P., and K. J. Richards, Effects of lateral mixing on the mean state and eddy activity of an equatorial ocean, J. Geophys. Res., 108(C12), 3371, doi:10.1029/2003JC001834, 2003.

\section{Introduction}

[2] Ocean models are used in a range of studies of the equatorial Pacific, from studies of the basic dynamics, thermodynamics, and circulation of the ocean to seasonal prediction of ENSO events. The models used vary from very simple and idealized models up to those using complex formulations such as ocean general circulation models (OGCMs). However, OGCMs have numerical and physical limitations in simulating all ocean processes. The lack of ability of coupled models to reproduce major features of the

\footnotetext{
${ }^{1}$ Now at Center for Weather Forecast and Climate Studies (CPTEC), National Institute for Space Research (INPE), Sao Paulo, Brazil.

Copyright 2003 by the American Geophysical Union. 0148-0227/03/2003JC001834\$09.00
}

tropical climatology may be attributed to a sensitivity to sub-grid scale processes as suggested by Neelin [1992]. Because of limitations of spatial resolution, physical processes that are not explicitly resolved have to be parameterized, usually by assuming that small-scale processes act in a diffusive manner. The magnitude of the associated diffusion coefficients for a given horizontal grid resolution is often chosen, somewhat arbitrarily, solely for reasons of numerical stability [Delecluse, 1994]. Previous studies, however, have demonstrated that mixing processes can play a crucial role in the dynamics and thermodynamics of numerical simulations. Ideally, a parameterization scheme should be based on sound physical reasoning. This is often not the case because of our lack of understanding of the physical processes involved. However, something we can do is to investigate the sensitivity of the system to the form 
of the imposed parameterization scheme, in order to ascertain the robustness of conclusions drawn from modeling studies.

[3] Lateral mixing plays an important role in determining the sea surface temperature (SST) in the equatorial Pacific as showed by Stockdale et al. [1993] in a model intercomparison. Maes et al. [1997] demonstrated the importance of horizontal mixing using the OPA OGCM [Madec et al., 1998] in the tropical Pacific basin by assessing the model sensitivity to a variation of 2 orders of magnitude in the eddy viscosity and diffusivity coefficients. They state that there is a nonlinear interplay between horizontal and vertical mixing of the model solution since a change in the lateral mixing characteristics affects the behavior of the model by changing the role of others parameters, for example, in the Equatorial UnderCurrent (EUC) regime and in vertical mixing. When the eddy dissipation is decreased, both the strength of the EUC and the SST in the cold tongue are increased. The sensitivity of the system to the orientation of mixing was investigated by Lengaigne et al. [2003]. They found that the upper part of EUC is deepened and the strength of the South Equatorial Current (SEC) increased for the equatorial Pacific and Atlantic Oceans. However, when mixing of both tracers and momentum along isopycnic surfaces is allowed, they find that the strength of EUC and SEC are simulated more realistically when compared with observations. They argue that the extra-equatorial circulation is improved when tracer is mixed along isopycnic surfaces compared with when both tracers and momentum are mixed along horizontal surfaces. On the basis of their findings, Lengaigne et al. [2003] suggested that for a better representation of tropical circulation in climate models, isopycnic mixing for tracers and momentum must be considered (see also Megann and New [2001], who use an isopycnic coordinate model).

[4] The above studies have all assumed that the viscosity and diffusion coefficients are constant across the whole of the model domain. In a region as variable as the tropical/extra-tropical Pacific it would be surprising if this were to be the case. Large et al. [2001] have investigated the effects of applying an anisotropic viscosity, which does improve their model integrations, but the value of the coefficient still needs to be of order $1.0 \times 10^{3} \mathrm{~m}^{2} \mathrm{~s}^{-1}$. As we see in this paper, and in the work of Richards and Edwards [2003], increasing resolution, with an appropriate decrease in diffusion coefficients, does not lead to an improved model integration in all aspects. There is still a need for unresolved processes to be modeled with an order $1.0 \times 10^{3} \mathrm{~m}^{2} \mathrm{~s}^{-1}$ diffusion coefficient. But what are the missing physics? One process that has the potential of impacting on the larger-scale dynamics of the region, and which will not be resolved in a conventional ocean model even at fine horizontal resolution, is the interleaving of water masses across the equator [see Richards and Banks, 2002]. The interleaving is confined to a few degrees either side of the equator. Richards [1998] argues that the effective diffusion is of order $1.0 \times 10^{3} \mathrm{~m}^{2} \mathrm{~s}^{-1}$, large enough to affect the dynamics of the system [cf. Maes et al., 1997] and indeed shown to do so in idealized studies such as those of Banks [1996] and Richards and Edwards [2003].
[5] Another feature of the equatorial Pacific is the presence of tropical instability waves (TIWs) on the eastern side of the Pacific [e.g., Legeckis, 1977; Chelton et al., 2000], which contribute to the heat budget of the cold tongue. The energetics of the TIW activity has been analyzed in an OGCM by Masina et al. [1999] at a fixed value of viscosity and tracer diffusion coefficients. The waves are affected by the prescribed mixing parameterization; however, the sensitivity of the wave activity to the form of the mixing parameterization needs to be ascertained. The purpose of this paper is to investigate the sensitivity of both the mean state and TIW activity of the equatorial Pacific to the strength and form of the mixing parameterization. The paper should be viewed as an extension of the work of Maes et al. [1997] and Lengaigne et al. [2003]. We choose, however, to study the sensitivity of the system in a rectangular domain with idealized forcing to simplify the interpretation of the results. The rest of paper is organized as follows. In section 2 the model configuration, parameterization, and experimental setup are described. In section 3 the model sensitivities to the magnitude, orientation, grid resolution, and form of the mixing are analyzed. The meridional heat transport is analyzed in section 4 , the model energetics is investigated in section 5, and the effects on TIW characteristics are considered in section 6. A summary and conclusions are presented in the last section.

\section{Model Configuration and Experiments Performed}

[6] OPA is a numerical ocean general circulation model (OGCM) designed for oceanic studies and its interactions with other components of the climate system, i.e., atmosphere, sea-ice, and biogeochemical tracers. This model has been used in many fields of oceanographic and climatic research, and an extensive reference list of OPA applications is given by Madec et al. [1998].

[7] The variables are distributed on a three-dimensional Arakawa C-type grid using prescribed horizontal (Z) levels. This OGCM solves the primitive equations following Bryan [1969] as referenced by Madec et al. [1998] with a large variety of physical options, and the prognostic variables are the three-dimensional velocity field and thermohaline variables. A leapfrog three-level centered time differencing scheme is used for nondiffusive processes. The first time step of this three-level scheme when starting from an ocean at rest is a forward step. The numerical techniques used to solve the primitive equations are based on the centered second-order finite difference approximation. A full description with all model formulations is given by Madec et al. [1998].

[8] For this study the model is configured in a rectangular equatorial domain, without bottom topography. The domain covers a region extending from $31^{\circ} \mathrm{S}$ to $31^{\circ} \mathrm{N}$ and $120^{\circ}$ in longitude (arbitrarily referred to as $1^{\circ}$ to $120^{\circ}$, from west to east) resembling the tropical Pacific Ocean. All lateral boundaries are closed using no-slip conditions. The model grid is stretched within the equatorial region and over the westernmost region of the domain to better resolve the equatorial current system and the western boundary currents, respectively, when a coarse grid resolution is used. We choose to use two grid resolutions. For 
Table 1. Description of the Numerical Experiments Performed ${ }^{\mathrm{a}}$

\begin{tabular}{ccccccc}
\hline SFC & Name & $A_{h}$ & $S S T_{c}$ & $E U C_{\max }$ & $M K E_{\text {avg }}$ & $E K E_{\text {avg }}$ \\
\hline HOR & Hor301 & $4.0 \times 10^{3}$ & 21.85 & 63.13 & 15.49 & 1.89 \\
& Hor302 & $2.0 \times 10^{3}$ & 21.72 & 88.14 & 22.30 & 4.33 \\
& Hor303 & $4.0 \times 10^{2}$ & 22.01 & 133.53 & 34.80 & 19.17 \\
& Hor304 & $4.0 \times 10^{2}+2.0 \times 10^{3}$ & 21.99 & 81.20 & 23.10 & 9.18 \\
ITM & Itm301 & $4.0 \times 10^{3}$ & 21.42 & 83.81 & 24.84 & 4.26 \\
& Itm302 & $2.0 \times 10^{3}$ & 21.60 & 97.34 & 28.38 & 8.65 \\
& Itm303 & $4.0 \times 10^{2}$ & 21.92 & 130.38 & 38.89 & 25.19 \\
& Itm304 & $4.0 \times 10^{2}+2.0 \times 10^{3}$ & 21.71 & 86.10 & 26.63 & 16.10 \\
\hline
\end{tabular}

${ }^{\mathrm{a}}$ Columns represent: lateral mixing orientation (HOR means horizontal mixing and ITM isopycnal mixing for tracers and momentum), experiment names, mixing coefficients $\left(A_{h}\right.$, units are in $\left.\mathrm{m}^{2} \mathrm{~s}^{-1}\right), S S T_{c}$ averaged over the Cold Tongue region $\left({ }^{\circ} \mathrm{C}\right)$, EUC maximum value $\left(\mathrm{cm} \mathrm{s}^{-1}\right)$, mean (MKE) and eddy kinetic energy (EKE) averaged zonally over the whole domain, from $8^{\circ} \mathrm{N}$ to $8^{\circ} \mathrm{S}$ and over the top $270 \mathrm{~m}$ (units are $\mathrm{cm}^{2} \mathrm{~s}^{-2}$ ).

the coarser of the two, the grid spacing in the meridional direction is $1 / 2^{\circ}$ between $5^{\circ} \mathrm{S}$ and $5^{\circ} \mathrm{N}$, increasing to $2^{\circ}$ by $10^{\circ} \mathrm{S}\left(10^{\circ} \mathrm{N}\right)$. The zonal grid spacing is $1 / 2^{\circ}$ at the western boundary, increasing to $1^{\circ}$ by longitude $10^{\circ}$, and remaining at this grid spacing over the rest of model domain. The fine grid resolution version has $1 / 4^{\circ}$ in the zonal direction covering all the domain, and in the meridional direction it has $1 / 4^{\circ}$ within the equatorial region extending from $5^{\circ} \mathrm{S}$ to $5^{\circ} \mathrm{N}$ increasing to $1^{\circ}$ toward the northern and southern boundaries. There are 31 levels in the vertical, with the highest resolution of approximately $10 \mathrm{~m}$ in the top $150 \mathrm{~m}$. Below this depth the resolution decreases down to $500 \mathrm{~m}$ near the ocean bottom at $5000 \mathrm{~m}$ depth, for both coarse and fine grid resolutions. Vertical mixing is computed using a prognostic turbulent kinetic energy (TKE) equation [Blanke and Delecluse, 1993]. The majority of the results presented here are from experiments using the fine grid resolution. We compare the results of experiments with the fine and coarse grid resolution to give an indication of the effects of grid resolution.

[9] All experiments are forced by Hellerman and Rosenstein [1983] climatology, zonally averaged monthly mean wind stress over the Pacific Ocean basin mapped onto the model domain. Temperature and salinity are initialized from zonally averaged values [Levitus and Boyer, 1994a, 1994b] and the ocean starts from rest. SST and sea surface salinity (SSS) are restored toward zonally averaged climatological observations [Levitus and Boyer, 1994a, 1994b]. Within $10^{\circ}$ of the northern and southern boundaries, both temperature and salinity are restored to climatology throughout the full depth of the domain. The results are analyzed after the fourth year of integration when the upper ocean solutions have reached a statistically quasi-steady state, in the upper ocean.

[10] The experiments carried out with the fine resolution model are shown in Table 1, and they are split in two groups according to the lateral (Laplacian) mixing orientation applied. In the first group, four experiments have tracers and momentum mixed along horizontal (HOR) surfaces, and in the second group, tracers and momentum are mixed along isopycnic surfaces (ITM). The momentum and tracer diffusivities are set to be the same and are referred, for simplicity, as $A_{h}$. In this study, different diffusion regimes are imposed on each experiment with the eddy viscosity and diffusivity coefficients varying from high to low values. In the first three regimes, the $A_{h}$ used is $4.0 \times 10^{3} \mathrm{~m}^{2} \mathrm{~s}^{-1}, 2.0 \times 10^{3} \mathrm{~m}^{2} \mathrm{~s}^{-1}$, and $4.0 \times$ $10^{2} \mathrm{~m}^{2} \mathrm{~s}^{-1}$, respectively.

[11] In the fourth regime a parameterization based on a representation of interleaving is applied. Our knowledge and understanding of interleaving in the equatorial Pacific is still far from complete, as stated by Richards [1998], and, because of relatively high levels of mixing and limited vertical resolution, interleaving is not represented in OGCMs. Richards and Edwards [2003] consider ways of parameterizing the effects of interleaving in OGCMs. As they remark, the most appropriate form for the parameterization depends on the physical mechanism for the formation of the layers and the controls limiting layer growth. Here, as a first step in accessing the importance of interleaving on the large-scale dynamics of the equatorial ocean, we will assume that the interleaving acts in a diffusive manner on the large scale and that the lateral diffusion coefficient can be written as

$$
A_{h}=A_{0}+A_{\text {add }} e^{\frac{-y^{2}}{L^{2}}}
$$

where $A_{0}$ is a constant background diffusion coefficient (here taken to be $4.0 \times 10^{2} \mathrm{~m}^{2} \mathrm{~s}^{-1}$ ) and $A_{\text {add }}$ represents the effect of interleaving on the large scale fields of velocity and tracers. The effect of interleaving is chosen to be maximum on the equator decreasing away from the equator on a length scale of $L$ (with $L=2^{\circ}$ of latitude). The dependency of $A_{\text {add }}$ on the state of the ocean depends very much on the assumptions made for the processes controlling the interleaving [see Richards, 1998]. However, we can estimate $A_{\text {add }}$ to be of order $\mathrm{O}\left(1.0 \times 10^{3} \mathrm{~m}^{2} \mathrm{~s}^{-1}\right)$. Here we will set $A_{\text {add }}=2.0 \times 10^{3} \mathrm{~m}^{2} \mathrm{~s}^{-1}$

[12] Table 1 lists not only the experimental details but also, for comparison, a number of model diagnostics: areaaveraged sea surface temperature $\left(S S T_{c}\right)$ within the cold tongue region, extending from $6^{\circ} \mathrm{N}$ to $6^{\circ} \mathrm{S}$ and $90^{\circ}$ to $119^{\circ}$ of longitude, and the mean (MKE) and eddy kinetic energy (EKE) zonally averaged over the whole domain, from $8^{\circ} \mathrm{N}$ to $8^{\circ} \mathrm{S}$ and over the top $270 \mathrm{~m}$. The results presented in Table 1 are discussed later.

\section{Mean State Analysis}

\subsection{Equatorial Current System}

[13] The zonal component of the annual mean velocity between $10^{\circ} \mathrm{S}$ and $10^{\circ} \mathrm{N}$ of latitude in the eastern region of the basin at $97^{\circ}$ longitude is shown in Figure 1 for varying $A_{h}$ and mixing orientation. All model experiments are able to reproduce the gross features of the equatorial current system: the two (northern and southern) branches of the South Equatorial Current (SEC) in the upper ocean flowing westward, the EUC flowing eastward with its maximum at the equator, and the North Equatorial Counter Current (NECC) between $6^{\circ} \mathrm{N}$ and $8^{\circ} \mathrm{N}$ (refer to Table 1 for the maximum values of the EUC).

[14] The model equatorial current system is found to be very sensitive to the level and form of lateral mixing. Decreasing the magnitude of the lateral mixing coefficient by 1 order of magnitude increases the strength of the EUC by $100 \%$ (Figures 1a-1d) with the EUC being narrower with lower values of diffusivity. Likewise, the strengths of 

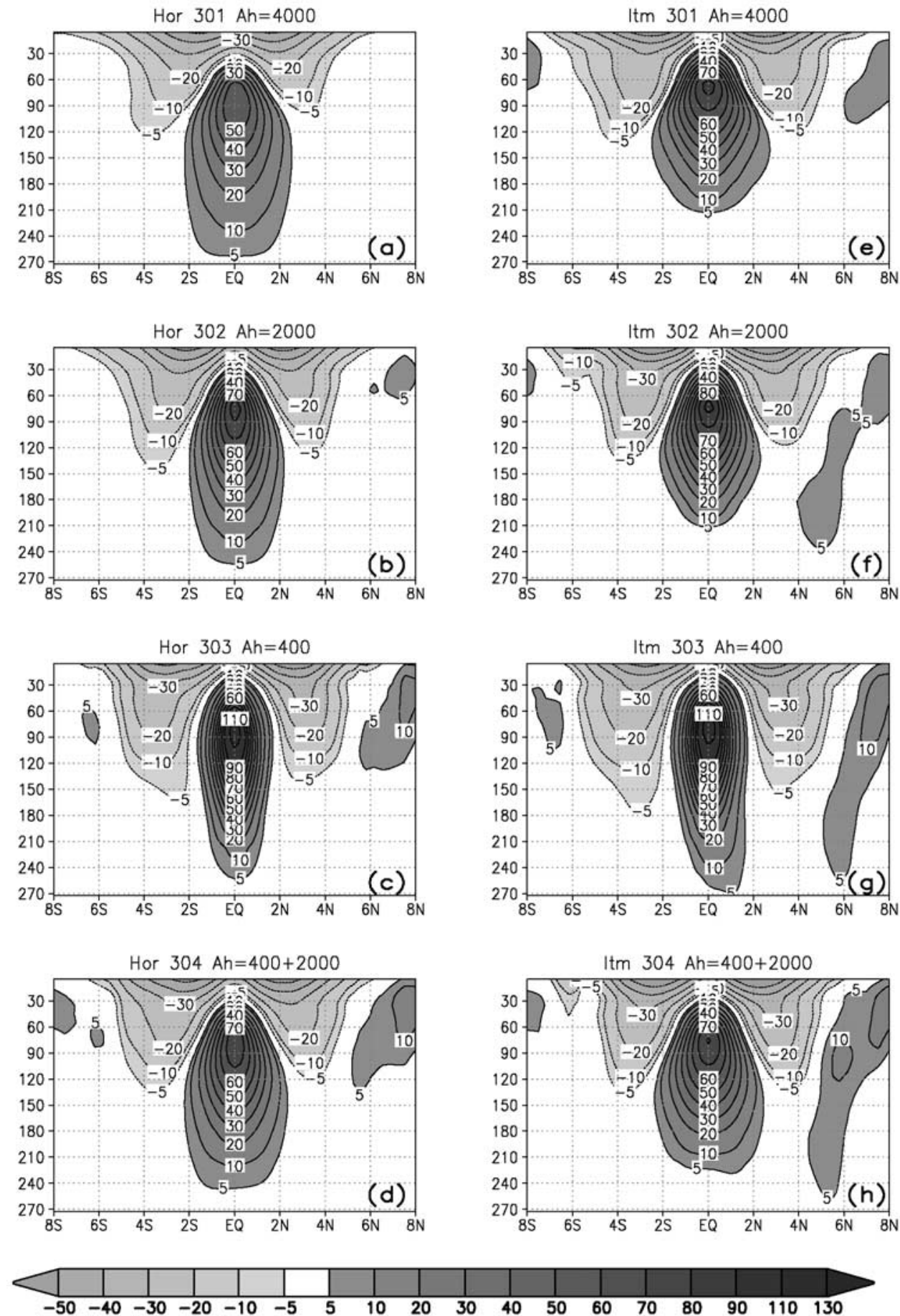

Figure 1. Vertical section of the zonal velocity component, $\mathrm{u}$, for the fine grid resolution experiments. (left) Experiments where tracer and momentum are mixed along horizontal surfaces (HOR), and (right) tracer and momentum being mixed along isopycnals (ITM). $A_{h}$ is the lateral mixing coefficient applied on the experiments. Units are in $\mathrm{cm} \mathrm{s}^{-1}$.

the SEC and NECC increase with decreasing $A_{h}$, with an associated deepening of both currents.

[15] Figure 2 shows the $S S T_{c}$ and $E U C_{\max }$ plotted for all lateral mixing coefficients used in the experiments. It should be noted that the additional mixing experiments (with $A_{h}$ given by equation (1)) are plotted using an abscissa value of $A_{h}=2.4 \times 10^{3} \mathrm{~m}^{2} \mathrm{~s}^{-1}$. We note two points from the general behavior of the system. The first is that although the $S S T_{c}$ is greatest for the lowest value of $A_{h}$, there is not a monotonic increase with decreasing $A_{h}$ for all series of experiments. The second is that, perhaps reassuringly, the points tend to cluster for the lowest value of $A_{h}$ for $S S T_{c}$ and $E U C_{\max }$. In other words, the characteristics of the model become less dependent on the formulism of lateral mixing and grid spacing at small values of the diffusivity. 

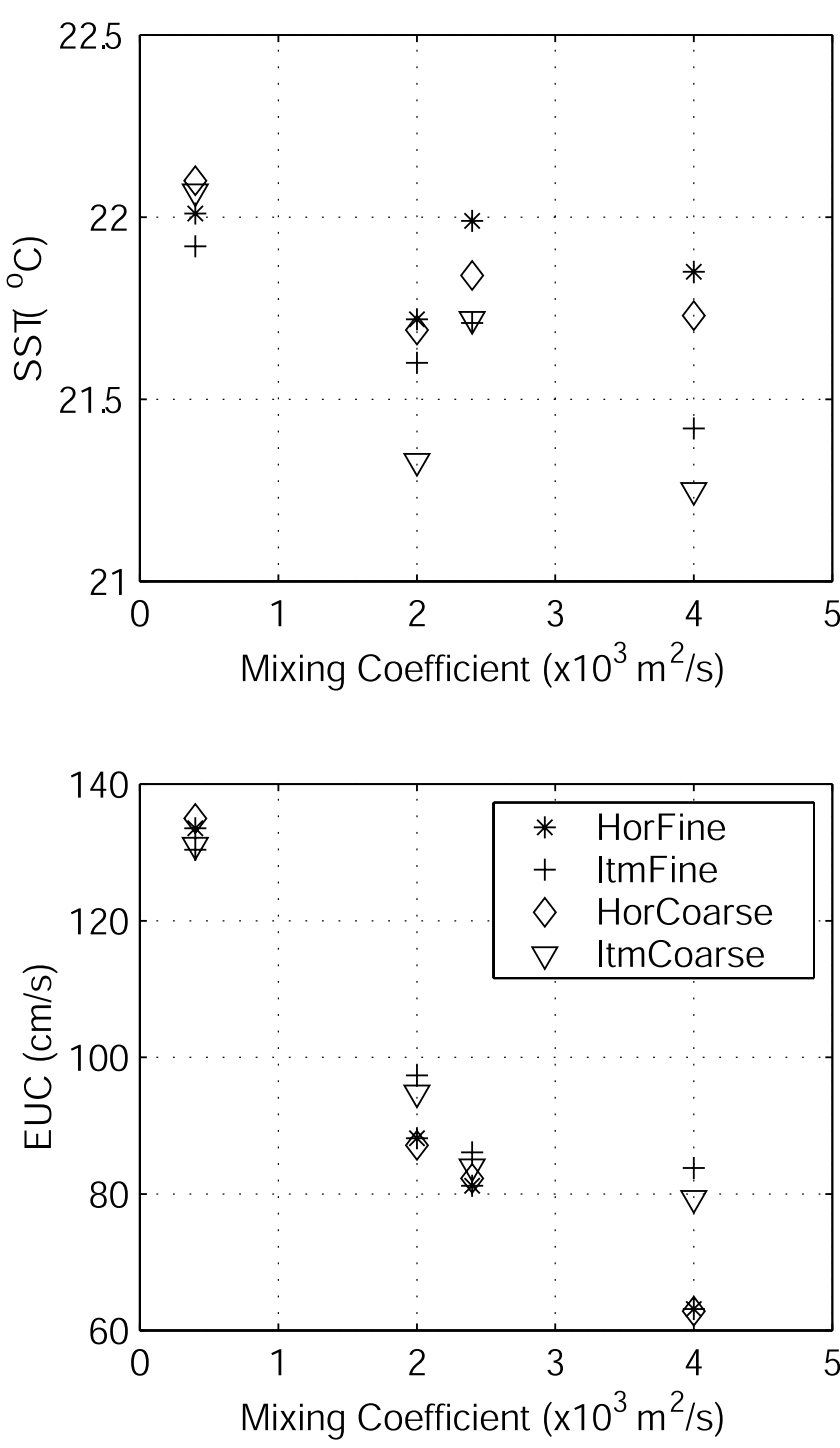

Figure 2. Gross properties of the model solutions. (a) SST averaged over the cold tongue region plotted against $A_{h}$ for all experiments. (b) $E U C_{\max }$ plotted against $A_{h}$ for all experiments. Note that symbols plotted at $A_{h}=2.4 \times$ $10^{3} \mathrm{~m}^{2} \mathrm{~s}^{-1}$ correspond to the additional lateral mixing experiments.

[16] With regards to the kinetic energy of the system we see, as expected, an increase in the mean kinetic energy (MKE) and eddy kinetic energy (EKE) when $A_{h}$ is decreased (see Table 1). The vertical transport (defined as the difference in the maximum and minimum of the meridional stream function of the overturning cells) was not found to vary significantly as the lateral mixing coefficients are varied (around $90 \mathrm{~Sv}$ with horizontal mixing and $85 \mathrm{~Sv}$ with isopycnic mixing), which is as expected since the vertical transport is controlled by the surface stress divergence. This is in contrast to Maes et al. [1997], who find that the strength of the meridional cell decreases as the lateral mixing coefficients are decreased, caused by an associated increase in the vertical mixing. The precise reason why we see a smaller variation in the strength of the meridional cell with the value of lateral mixing is unclear, but presumably is related to a smaller variation in vertical mixing.

\subsection{Mixing Orientation}

[17] In general, the experiments with the mixing of tracers and momentum (ITM) along isopycnic surfaces produce stronger currents, increasing the EUC velocity and both north and south branches of the SEC and also a better defined NECC compared with experiments when tracers and momentum are mixed horizontally (HOR) (see Figure 1 and Table 1). We find, in accord with Lengaigne et al. [2003], that rotating mixing to be along isopycnic surfaces reduces the effective diapycnal diffusion. This gives a tighter pycnocline and a speed-up of the equatorial current system. However, the differences between experiments with different mixing orientation are dependent on both the level of mixing and the numerical grid. For instance, the percentage increase of the $E U C_{\max }$ gain from horizontal to isopycnic mixing is $31 \%, 10 \%$, and $-2 \%$, for $A_{h}=4.0 \times 10^{3} \mathrm{~m}^{2} \mathrm{~s}^{-1}, A_{h}=2.0 \times$ $10^{3} \mathrm{~m}^{2} \mathrm{~s}^{-1}$, and $A_{h}=4.0 \times 10^{2} \mathrm{~m}^{2} \mathrm{~s}^{-1}$, respectively. Note that the EUC with isopycnic diffusion slows down slightly (compared to horizontal diffusion) for the low diffusion case. We also note that the differences in the SST of the cold tongue, $S S T_{c}$, for horizontal and isopycnic mixing and with $A_{h}=2.0 \times 10^{3} \mathrm{~m}^{2} \mathrm{~s}^{-1}$ is $0.4^{\circ} \mathrm{C}$ for the coarse grid experiments but only $0.1^{\circ} \mathrm{C}$ for the fine grid experiments.

\subsection{Enhanced Equatorial Mixing}

[18] The results of the experiments with enhanced mixing restricted to a few degrees either side of the equator show that the system is sensitive to such mixing, where here we are taking the enhanced mixing to be representative of the interleaving of water masses. Solutions with enhanced equatorial mixing (see Figures $1 \mathrm{~d}$ and $1 \mathrm{~h}$ ) are somewhat intermediate between those with moderate and low (but constant) diffusion. For instance, the enhanced equatorial mixing keeps the core speed of the EUC to a modest value, while the speed of the flow away the equator (e.g., the NECC) is now similar to that of the low diffusion case (see Table 1). The MKE of the enhanced mixing case is similar to that with a constant $A_{h}=2 \times 10^{3} \mathrm{~m}^{2} \mathrm{~s}^{-1}$. This is not so for the EKE, which has significantly higher values for the enhanced mixing case. The characteristics of the eddy field will be discussed further in section 5 .

[19] The strength of the EUC with enhanced equatorial mixing is consistent with the speed we could expect with a constant diffusivity coefficient (see Figure 2b). However, the average SST of the cold tongue region, $S S T_{c}$, is elevated above that for the equivalent constant $A_{h}$ case by as much as $0.5^{\circ} \mathrm{C}$ of the experiment with the coarse grid and isopycnic mixing (Table 1). Although the rise in the average SST is smaller for the other experiments, locally there are similar $\mathrm{O}\left(0.5^{\circ} \mathrm{C}\right)$ increases over an appreciable area in all experiments. This increased value of $S S T_{c}$ is brought about by the enhanced tropical instability wave activity allowed by the reduced levels of diffusion away from the equator (see section 6).

\section{Meridional Heat Transport}

[20] A primary condition for an OGCM to be a good tool to couple with an atmospheric model is its capacity to represent 

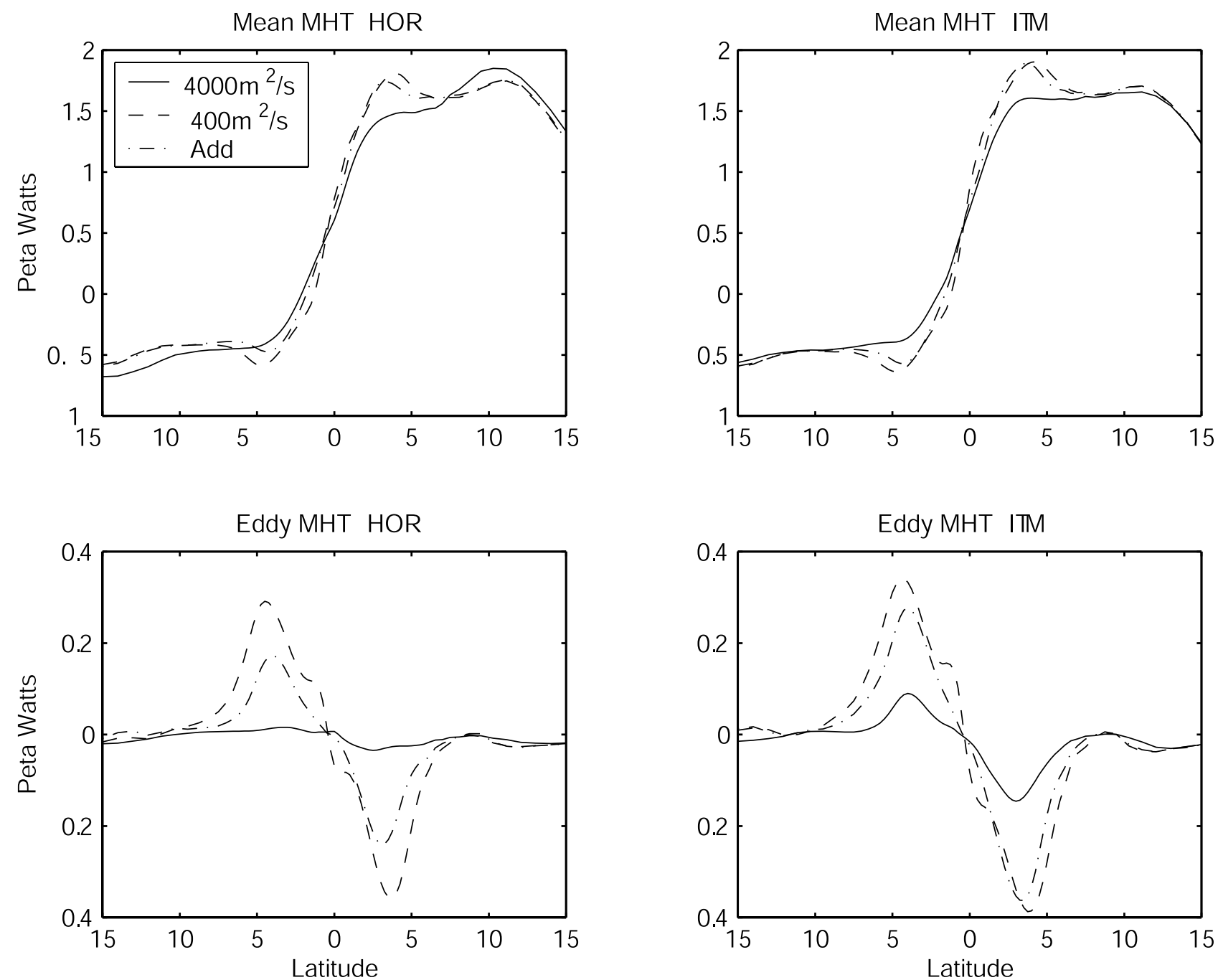

Figure 3. Meridional heat transport (MHT) (units are $10^{15}$ watts) for the fine grid resolution experiments. (left) HOR, mixing tracer and momentum along horizontal surface and (right) ITM, mixing tracer and momentum along isopycnal surface. Solid line, $A_{h}=4.0 \times 10^{3} \mathrm{~m}^{2} \mathrm{~s}^{-1}$; dashed line, $A_{h}=4.0 \times$ $10^{2} \mathrm{~m}^{2} \mathrm{~s}^{-1}$; dash-dotted line, additional mixing experiment.

the equatorial thermal structure, since the surface layers will have a strong impact on the atmospheric circulation, for example, the ENSO phenomenon. The ocean-atmosphere system is a large heat engine where the sun is the main source of energy. A great part of this incoming heat is redistributed in the ocean by the wind-generated currents, transient systems, and the thermohaline circulation.

[21] Here we will consider the integrated meridional heat flux across a zonal section ( $x$ longitude versus $z$ depth) of the basin, given by

$$
M H T_{T o t}=\rho_{0} C_{p} \iint \nu \theta d x d z
$$

where $M H T_{T o t}$ is the total meridional heat transport, $v$ is the meridional velocity, $\theta$ is potential temperature, $\rho_{0}$ is the mean seawater density (taken to be $1000 \mathrm{~kg} \mathrm{~m}^{-3}$ ), and $C_{p}$ is the specific heat capacity ( $4093 \mathrm{Jkg}^{-1}{ }^{\circ} \mathrm{K}^{-1}$ ). The contributions by the time mean and eddy components of the flow can be calculated by decomposing $v$ and $T$ into their time mean and fluctuating components, respectively, i.e., $v=\bar{v}+v^{\prime}$ and $\theta=\bar{\theta}+\theta^{\prime}$, and substituting in equation (2). Thus mean and eddy components of the meridional heat transport are given by

$$
\begin{gathered}
M H T_{\text {Mean }}=\rho_{0} C_{p} \iint \bar{v} \bar{\theta} d x d z \\
M H T_{E d d y}=\rho_{0} C_{p} \iint \nu^{\prime} \theta^{\prime} d x d z,
\end{gathered}
$$

respectively.

[22] The mean and eddy meridional heat fluxes using the fine grid resolution are shown in Figure 3. Similar characteristics are displayed by the coarse grid model (not shown). The analysis is done for the experiments with the largest and smallest diffusivity coefficients, and with additional mixing, namely $A_{h}=4.0 \times 10^{3} \mathrm{~m}^{2} \mathrm{~s}^{-1}, A_{h}=4.0 \times 10^{2} \mathrm{~m}^{2} \mathrm{~s}^{-1}$ and $A_{h}=2.0 \times 10^{3} \mathrm{~m}^{2} \mathrm{~s}^{-1}+4.0 \times 10^{2} \mathrm{~m}^{2} \mathrm{~s}^{-1}$, respectively. As shown in previous studies [Hastenrath, 1982; Philander, 1990], the Pacific Ocean has a characteristic poleward heat transport caused by the strong meridional divergence of the equatorial surface currents and subsurface convergence, 
moving warm surface waters poleward while colder waters return equatorward, mainly within the thermocline region. Here we find the mean heat flux is larger in the Northern Hemisphere compared to that in the south.

[23] The mean meridional heat flux in the experiments performed with the fine grid resolution using different mixing coefficients show small differences between them (Figures $3 \mathrm{a}$ and $3 \mathrm{c}$ ). There is an asymmetry in the heat flux with the region of no net meridional flux located at $3^{\circ} \mathrm{S}$. The largest differences between the experiments are located between $0^{\circ}$ and $5^{\circ} \mathrm{N}$ in the region where the TIWs occur, and for the high diffusion case, around $10^{\circ} \mathrm{N}$ with tracers and momentum being mixed along horizontal surfaces. The high diffusivity horizontal mixing experiment shows a single peak in the mean heat flux occurring around $10^{\circ} \mathrm{N}$. As the lateral mixing coefficient is decreased, the mean heat flux is increased within the TIW region giving a second peak.

[24] As the diffusivity is increased, the eddy heat transport, which fluxes heat down-gradient toward the equator, is reduced as the eddies (and TIWs) are damped (Figures $4 \mathrm{~b}$ and $4 \mathrm{~d})$. This effect is strongest with horizontal mixing when $A_{h}=4.0 \times 10^{3} \mathrm{~m}^{2} \mathrm{~s}^{-1}$, with the eddy transport almost completely damped out. The maximum difference in eddy heat flux between the highest and lowest diffusion cases reaches almost $0.4 \mathrm{PW}$. There is a corresponding change in the amplitude of the mean heat flux. Generally, the eddy heat fluxes are larger for the isopycnic mixing cases, with the difference between horizontal and isopycnic mixing being reduced as the diffusion coefficient is reduced. The magnitude of the eddy flux peaks at around $4^{\circ} \mathrm{N}$ and $4^{\circ} \mathrm{S}$ with indications of a secondary peak (or at least shoulder) forming closer to the equator as the diffusivity is reduced.

\section{Energetics}

\subsection{Kinetic Energy Distribution}

[25] In an effort to understand and evaluate the energetics of the mean state and transients generated in the numerical experiments, a kinetic energy analysis is performed. Analogous to the heat flux analysis, we divide the total kinetic energy, $K_{t}$, into the time mean kinetic energy, $\bar{K}_{m}$, and eddy kinetic energy, $K_{e}$. Thus,

$$
K_{t}=\bar{K}_{m}+K_{e}
$$

where

$$
\begin{gathered}
K_{t}=\frac{1}{2} \rho\left(u^{2}+v^{2}\right), \\
\bar{K}_{m}=\frac{1}{2} \rho\left(\bar{u}^{2}+\bar{v}^{2}\right), \\
K_{e}=\frac{1}{2} \rho\left(u^{\prime 2}+v^{\prime 2}\right) .
\end{gathered}
$$

In this case, the time mean is taken over the last year of the experiments.

[26] Figure 4 shows a vertical section of the kinetic energy in the eastern part of the domain at $97^{\circ}$ of longitude. Shaded areas represent $\bar{K}_{m}$, while $K_{e}$ is represented by solid lines. The $K_{e}$ indicates the region where the energy of the eddies (here associated with TIW activity) is located, while the $\bar{K}_{m}$ represents the energy structure of the mean flow. The analysis is performed over the first $270 \mathrm{~m}$ of depth since the major eddy activity is confined within this depth. In all cases the most energetic region is between approximately $6^{\circ} \mathrm{S}$ and $6^{\circ} \mathrm{N}$ and is where the strongest gradients in the equatorial currents and temperature occur. The most energetic regions of the mean state are where the EUC and SEC north and south branches are located. $\bar{K}_{m}$ is increased when the diffusivity is reduced, following the same pattern as the EUC and SEC velocity and also showing largest values for the experiments performed with the fine grid resolution as shown in Figure 4 when compared with the coarse resolution ones (not shown). The distribution of $K_{e}$ has a maximum at the surface, and from there the energy decreases, splitting downward into two energetic branches. One goes down between the EUC and the southern SEC branch in a region of strong shear between these two currents. The northern branch of $K_{e}$ is slightly more energetic than the southern and is in the region between the EUC and SEC northern branch. For a given diffusion coefficient, both the mean and eddy kinetic energy are greatest when tracers and momentum are mixed along isopycnals (Figures $4 \mathrm{e}$ to $4 \mathrm{~h}$ ), following the same pattern as the current speed. For instance, when $A_{h}=2.0 \times 10^{3} \mathrm{~m}^{2} \mathrm{~s}^{-1}$ (Figure 4f) $K_{e}$ is twice as large (having a maximum of $50 \mathrm{~m}^{2} \mathrm{~s}^{-2}$ ) when compared with the horizontal mixing on Figure $4 \mathrm{~b}$ (maximum of $25 \mathrm{~m}^{2} \mathrm{~s}^{-2}$ ).

[27] There is a marked change in the distribution of eddy kinetic energy as the diffusion coefficient is reduced to $A_{h}=$ $4.0 \times 10^{2}$ (Figures $4 \mathrm{c}$ and $4 \mathrm{~g}$ ). At higher values of $A_{h}$, there are maxima in $K_{e}$ either side of the equator (the greater being toward the north). For the lowest value of $A_{h}$, there is now an intense maximum centered on the equator with subsurface maxima to the north and south. With enhanced mixing close to the equator (Figures $4 \mathrm{~d}$ and $4 \mathrm{~h}$ ) the equatorial maximum in $K_{e}$ is eradicated, but the northerly and southerly subsurface maxima remain.

\subsection{Energy Transformation Analysis}

[28] Strong current shear and temperature gradients occur within the tropical Pacific region and as a consequence TIWs are generated in this region. However, the generating mechanism for these waves is not completely understood and is still under discussion by the scientific community. Barotropic instability, initiated by the shear between the EUC and SEC, and also between the EUC and NECC, is attributed as an important mechanism for TIW generation [Luther and Johnson, 1990; Qiao and Weisberg, 1998]. However, these waves have other processes contributing to their generation, such as baroclinic instability, as argued by Luther and Johnson [1990] and Masina et al. [1999], acting as a trigger mechanism further north and south of equator.

[29] In this section we analyze the energetics of the model experiments simulated using different mixing regimes. To analyze the influence and energy source of the equatorial waves, the barotropic and baroclinic production terms of the eddy kinetic energy equation are computed, following a similar approach used by Masina et al. [1999]. For the sake of brevity, only the dominant terms in the eddy kinetic energy equation will be discussed here. The full equations are given by Masina et al. [1999]. 

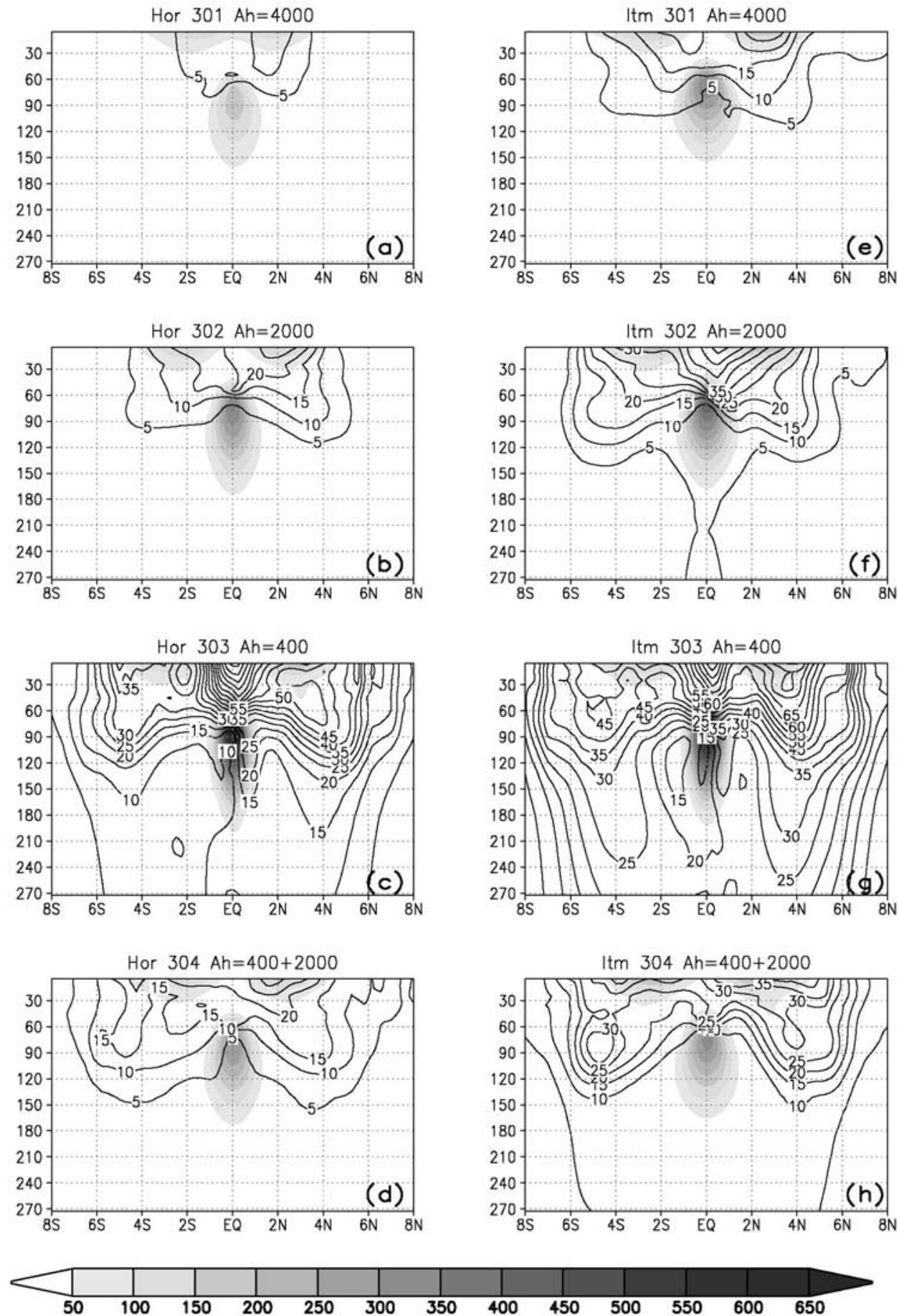

Figure 4. Mean kinetic energy (MKE) (shading) and eddy kinetic energy (EKE) for the fine model grid resolution experiments. (left) Horizontal mixing for tracers and momentum (HOR) and (right) isopycnal mixing (ITM).

[30] The eddy kinetic energy equation is

$$
\begin{aligned}
\frac{\partial K_{e}}{\partial t} & +\overline{\mathbf{u}} \cdot \nabla K_{e}+\bar{w} K_{e z}+\mathbf{u}^{\prime} \cdot \nabla K_{e}+w^{\prime} K_{e z} \\
& =-\mathbf{u}^{\prime} \cdot \nabla p^{\prime}+\rho_{0}\left[-\mathbf{u}^{\prime} \cdot\left(-\mathbf{u}^{\prime} \cdot \nabla \overline{\mathbf{u}}\right)-\mathbf{u}^{\prime} \cdot\left(w^{\prime} \overline{\mathbf{u}}_{\mathbf{z}}\right)+\mathbf{u}^{\prime} \cdot\left(\overline{\mathbf{u}^{\prime} \cdot \nabla \mathbf{u}^{\prime}}\right)\right. \\
& \left.+\mathbf{u}^{\prime} \cdot\left(\overline{w^{\prime} \mathbf{u}^{\prime}}\right)+A_{h}\left(\mathbf{u}^{\prime} \cdot \nabla^{2} \mathbf{u}^{\prime}\right)+\mathbf{u}^{\prime} \cdot\left(A_{v} \mathbf{u}_{z}^{\prime}\right)_{z}\right],
\end{aligned}
$$

where $K_{e}$ is the eddy kinetic energy, $\mathbf{u}=u \hat{\mathbf{x}}+\nu \hat{\mathbf{y}}$ is the horizontal velocity vector, and $\nabla$ is the horizontal divergence. The terms on the left-hand side of (equation (7)) represent the local tendency, and horizontal and vertical advection of $K_{e}$ by the time mean and fluctuating flow, respectively. The first term on the right-hand side of equation (7) represents the pressure work divergence done by the eddies that tend to redistribute the kinetic energy spatially. The second and third terms are the barotropic energy conversion terms between the mean flow and eddies through deformation work. The fourth and fifth represent 
BAROTROPIC

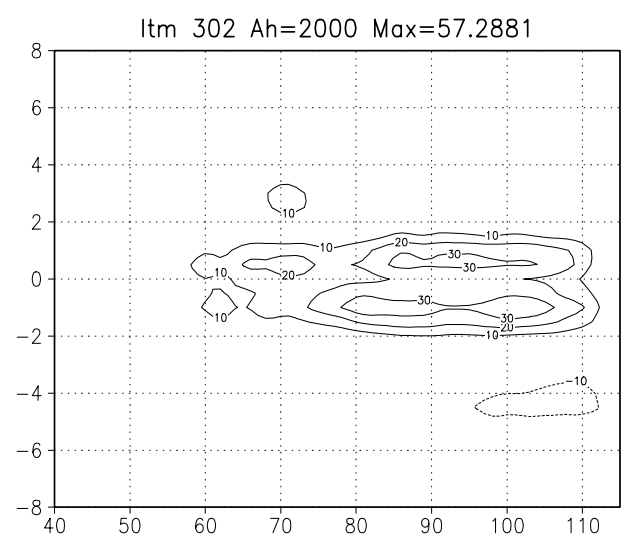

(a)

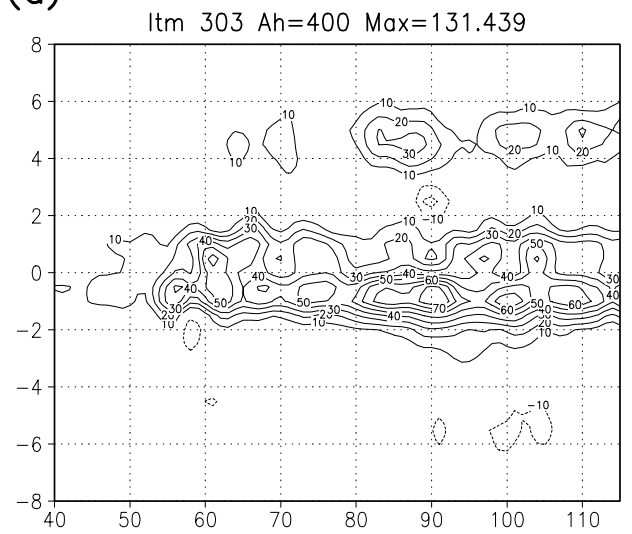

(b)

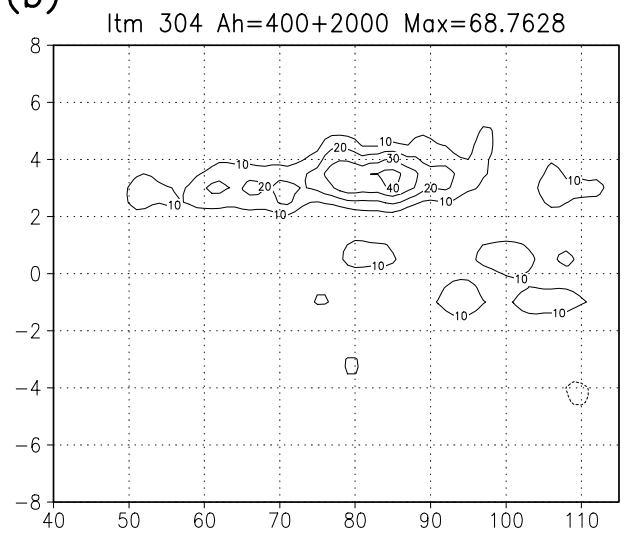

(c)
BAROCLINIC

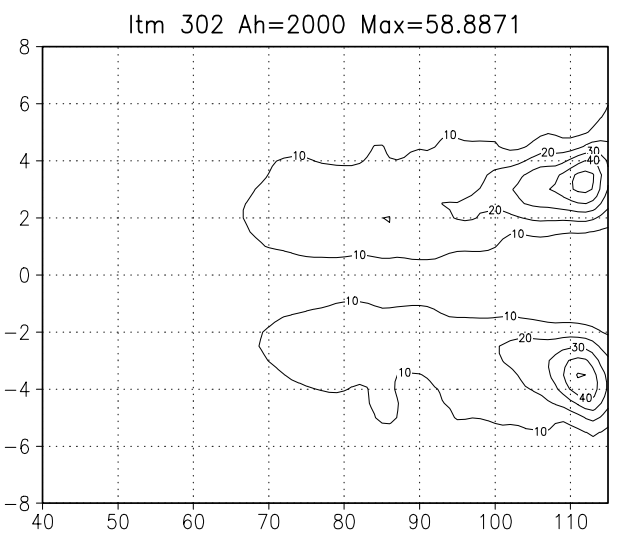

(d)

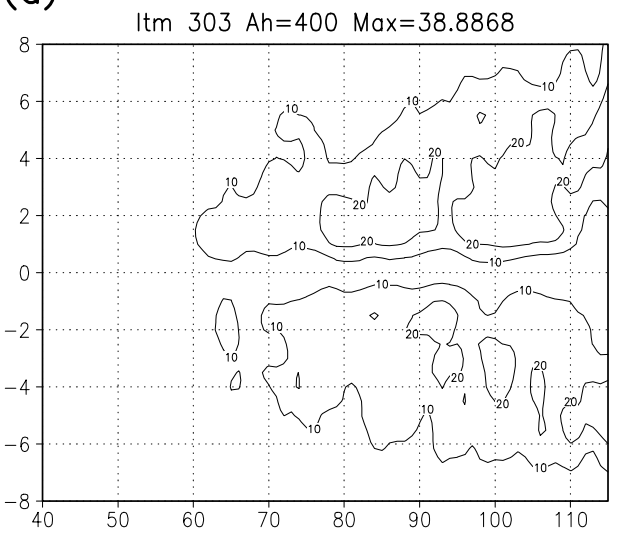

(e)

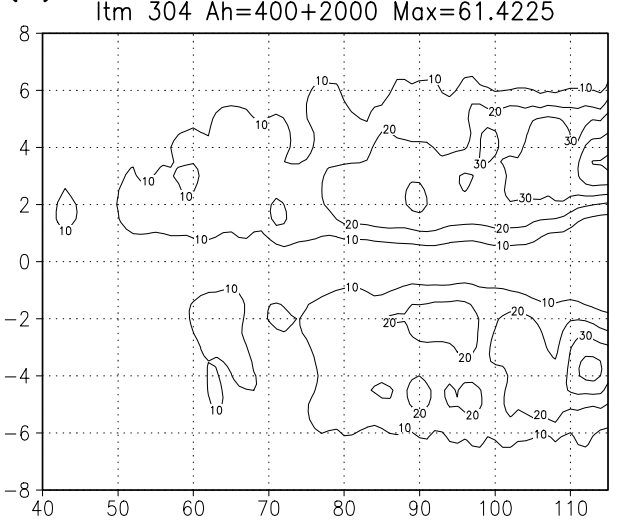

(

Figure 5. Horizontal sections at $5 \mathrm{~m}$ depth of the $(\mathrm{a}-\mathrm{c})$ time mean barotropic conversion term and $(\mathrm{d}-\mathrm{f})$ time mean baroclinic conversion term. Experiments use (top) $A_{h}=2.0 \times 10^{3} \mathrm{~m}^{2} \mathrm{~s}^{-1}$, (middle) $A_{h}=4.0 \times$ $10^{2} \mathrm{~m}^{2} \mathrm{~s}^{-1}$, and (bottom) additional mixing. The units are in $\mu \mathrm{Wm}^{-3}$.

the divergence of $K_{e}$ by the fluctuating velocity field. The two last terms represent the horizontal and vertical eddy dissipation. Calculation of the various terms is made from a time series of instantaneous fields taken every 5 days with the time mean (given by an overbar) taken as the annual average. The conversion of mean kinetic energy into eddy kinetic energy occurs when the horizontal or vertical deformation work terms in equation (7) are positive. The horizontal deformation term of equation (7) is known as barotropic conversion, while the vertical term is KelvinHelmholtz conversion.
[31] Assuming the hydrostatic approximation, the eddy divergence pressure flux, $\mathbf{u}^{\prime} \cdot \nabla p^{\prime}$, in equation (7) can be written as [cf. Masina et al., 1999]

$$
\mathbf{u}^{\prime} \cdot \boldsymbol{\nabla} p^{\prime}=-\boldsymbol{\nabla} \cdot\left(\mathbf{u}^{\prime} p^{\prime}\right)-\left(w^{\prime} p^{\prime}\right)_{z}-g \rho^{\prime} w^{\prime} .
$$

[32] The first two terms on the right-hand side, which spatially redistribute eddy kinetic energy, sum to zero when integrated over the domain. The last term on the right-hand side represents the conversion of mean available potential energy to eddy kinetic energy, $K_{e}$; that is, eddy kinetic 


\section{BAROTROPIC}

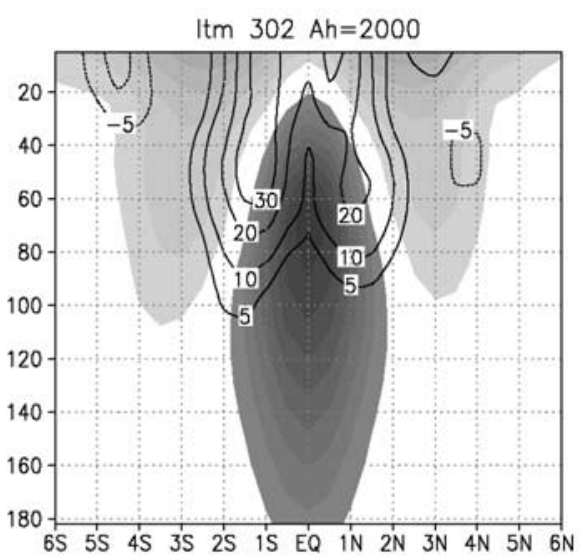

(a)

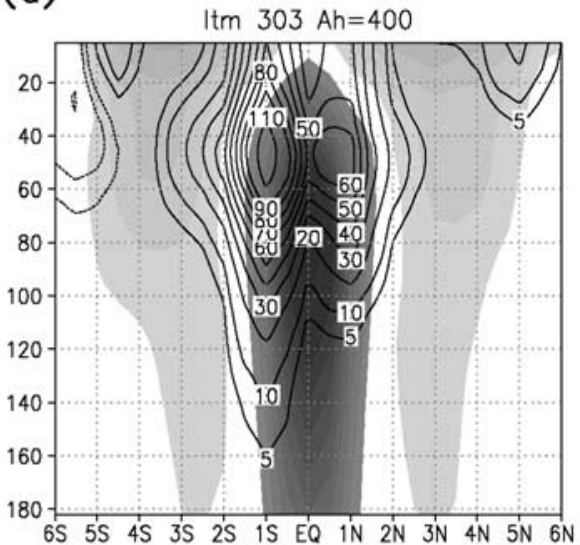

(b)

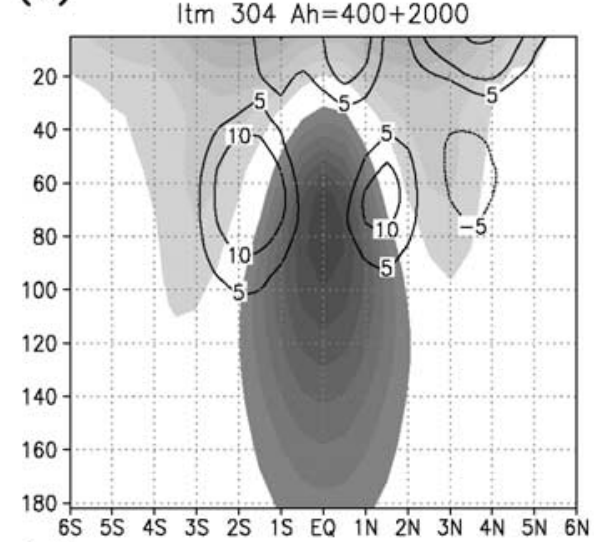

(c)
BAROCLINIC

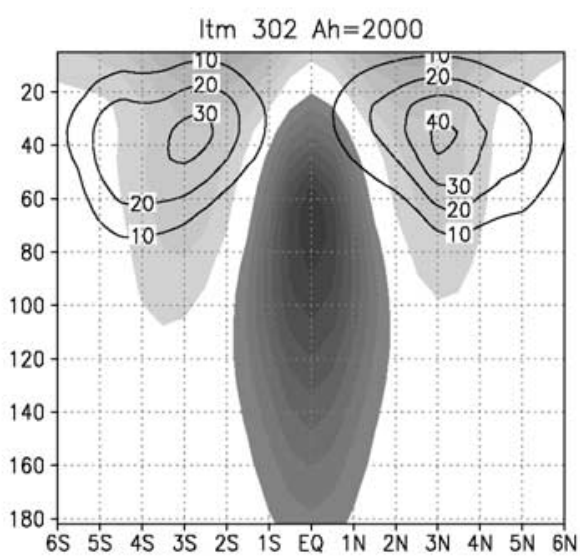

(d)

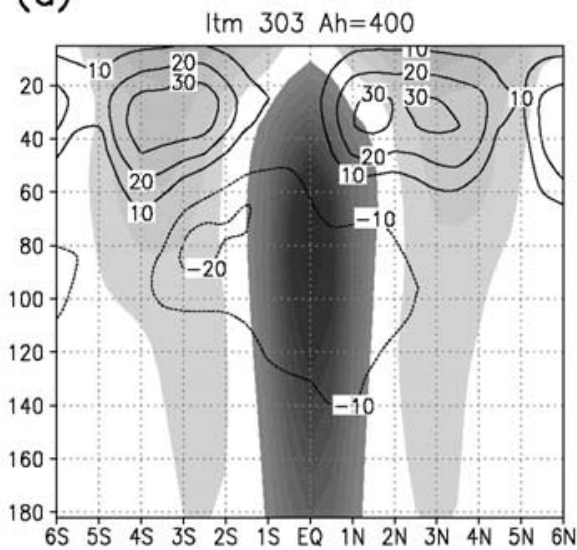

(e)

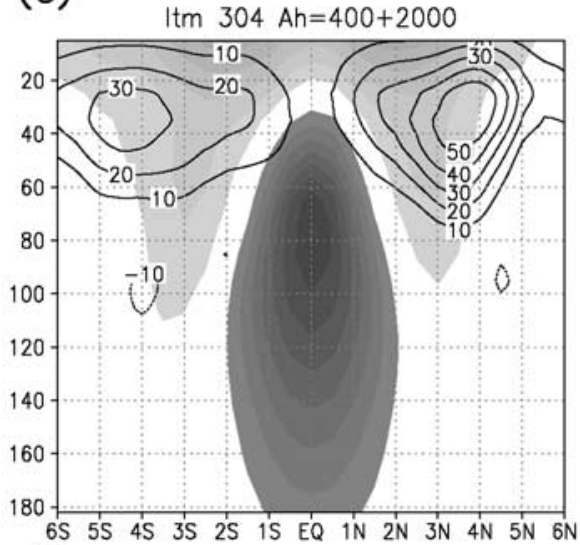

(f)

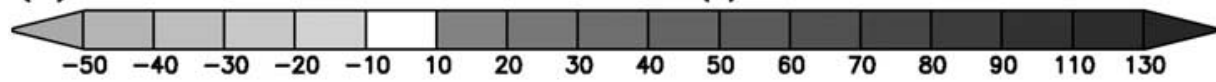

Figure 6. Vertical sections at $97^{\circ}$ longitude of the $(\mathrm{a}-\mathrm{c})$ time mean barotropic conversion term and $(\mathrm{d}-\mathrm{f})$ time mean baroclinic conversion term. Experiments use (top) $A_{h}=2.0 \times 10^{3} \mathrm{~m}^{2} \mathrm{~s}^{-1}$, (middle) $A_{h}=4.0 \times$ $10^{2} \mathrm{~m}^{2} \mathrm{~s}^{-1}$, and (bottom) additional mixing, respectively. The units are in $\mu \mathrm{Wm}^{-3}$. Shaded regions show the zonal velocity component; units are in $\mathrm{cm} \mathrm{s}^{-1}$.

energy is gained through the vertical deformation work. This term is known as the baroclinic conversion term, and we restrict the baroclinic analysis to this term.

[33] We find that the dominant production terms in equation (7) are $-\rho\left(\overline{u^{\prime} v^{\prime}} \frac{\partial \bar{u}}{\partial v}\right)$ and $-g \rho^{\prime} w^{\prime}$ (see equation $(8)$ ); hereinafter, these terms are referred to as the barotropic and baroclinic conversion terms, respectively. The other horizontal deformation work terms, for example, $-\rho\left(\overline{u^{\prime} u^{\prime}} \frac{\partial \bar{u}}{\partial x}\right)$ are smaller than the barotropic term, and they are not considered here.

[34] Horizontal sections at $5 \mathrm{~m}$ depth (the upper level of the model) (Figure 5) show that there are three primary 


\section{BAROTROPIC LAT $=1 \mathrm{~N}$}

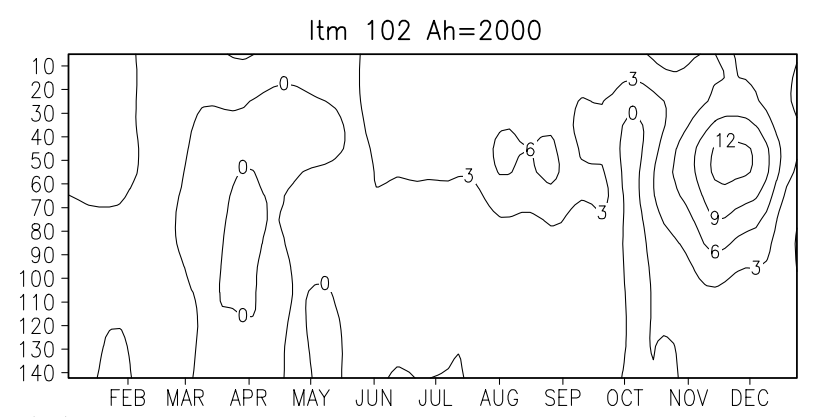

(a)

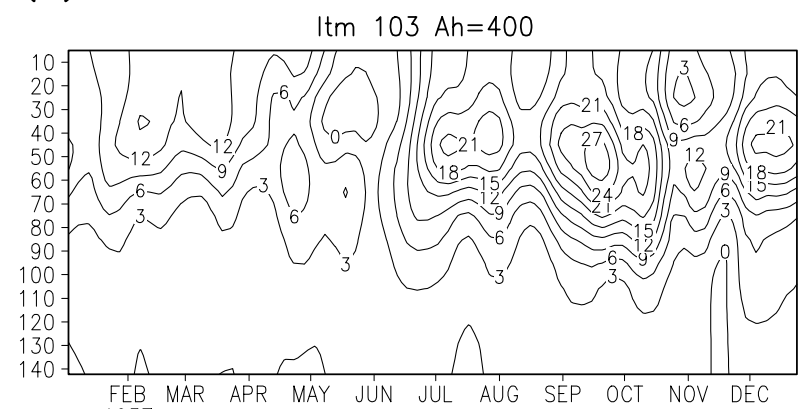

(b)

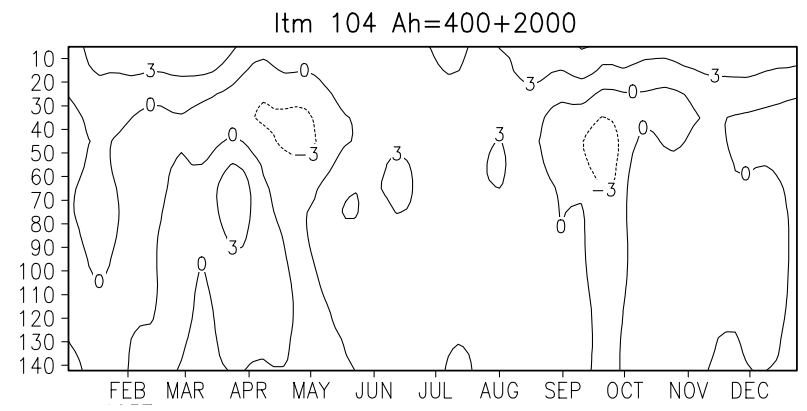

(c)
BAROCLINIC LAT $=3 \mathrm{~N}$

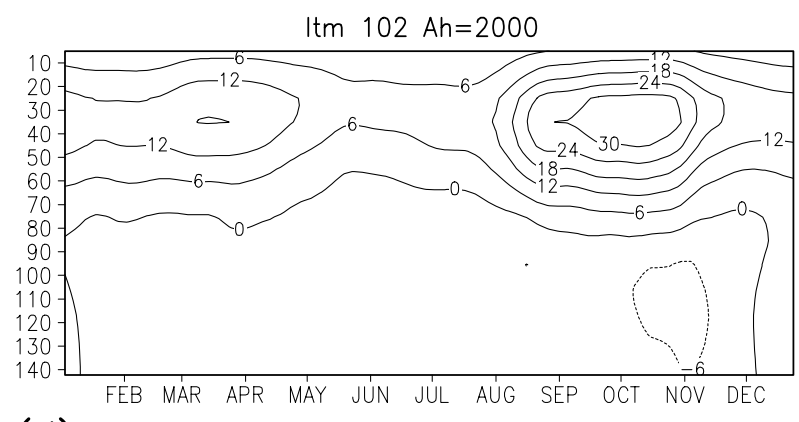

(d)

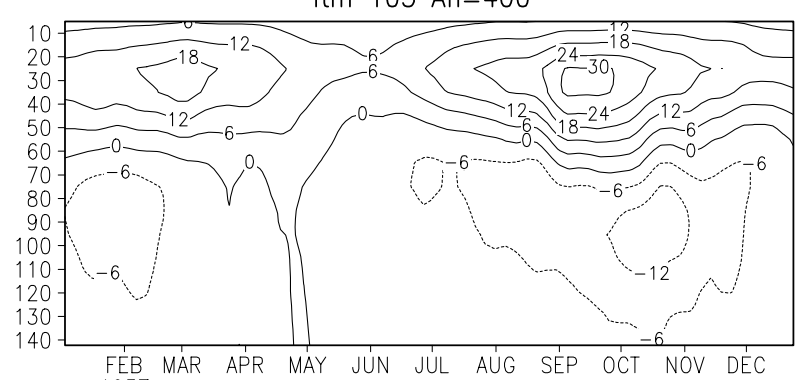

(e)

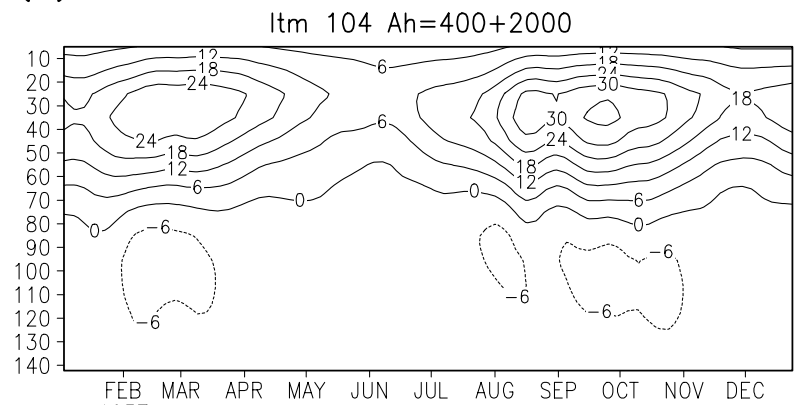

(f)

Figure 7. Time-depth sections of $(a-c)$ barotropic and $(d-f)$ baroclinic conversion terms, averaged over the $90^{\circ}$ to $110^{\circ}$ longitudinal band and between $8^{\circ} \mathrm{S}$ and $8^{\circ} \mathrm{N}$. Experiments use (top) $A_{h}=2 \times 10^{3} \mathrm{~m}^{2} \mathrm{~s}^{-1}$, (middle) $A_{h}=4 \times 10^{2} \mathrm{~m}^{2} \mathrm{~s}^{-1}$, and (bottom) additional mixing. The units are in $\mu \mathrm{Wm}^{-3}$.

regions of eddy kinetic energy production. When $A_{h}=2.0 \times$ $10^{3} \mathrm{~m}^{2} \mathrm{~s}^{-1}$ (Figure 5a), the barotropic conversion shows a maximum in the equatorial region and is related to the conversion of mean flow kinetic energy into eddy energy due to the meridional current shear.

[35] The vertical distribution of the time mean barotropic and baroclinic conversion terms in the eastern part of the domain $\left(97^{\circ}\right.$ longitude) is presented in Figure 6. Overall, the changes in the patterns of barotropic and baroclinic conversion with respect to the level of lateral mixing are similar to those at the surface. However, note that the maxima in values are generally subsurface between 40 to $60 \mathrm{~m}$ depth. The barotropic conversion is primarily produced by the shear between the EUC and the northern and southern limbs of the SEC. An exception is the surface maximum in barotropic conversion brought about by the shear between the SEC and NECC for low values of lateral mixing. The other noteworthy feature is the much greater depth penetration of the barotropic conversion when the lateral mixing is low close to the equator.
[36] The magnitude and spatial distribution of the barotropic conversion are sensitive to the mixing scheme applied. As the mixing coefficient is decreased, the barotropic conversion is increased as a consequence of the increase on the current shear (see, for instance, Figure 1). In the case where low mixing is used (Figures $5 \mathrm{~b}$ and $6 \mathrm{~b}$ ), there is a considerable increase (more than a factor of 2) in the production of $K_{e}$ by barotropic conversion in the equatorial region as the EUC strengthens and tightens. For low $A_{h}$, there is a secondary maximum of energy occurring just north of $4^{\circ} \mathrm{N}$. This secondary maximum is due to the stronger current shear between the SEC and NECC.

[37] For the enhanced equatorial mixing case (Figures $5 \mathrm{c}$ and $6 c$ ) the pattern is different from either the high or low diffusion cases. The enhanced mixing suppresses the barotropic conversion on the equator, with an off-equator region of high values of conversion centered on $3^{\circ} \mathrm{N}$ (i.e., southward of that for low diffusion and somewhat to the west).

[38] On the other hand, the pattern of the time mean baroclinic conversion term is relatively insensitive to the 
a

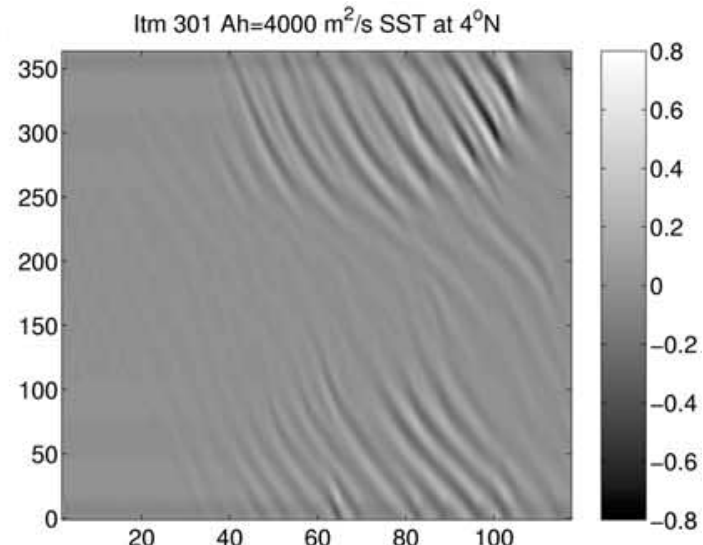

b

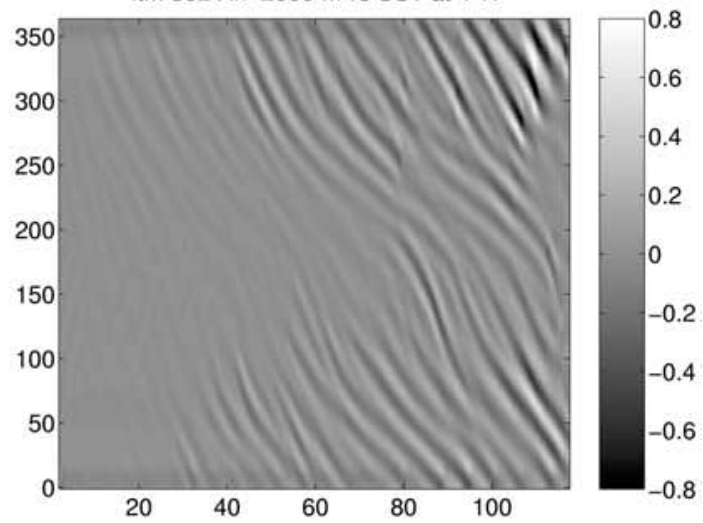

c

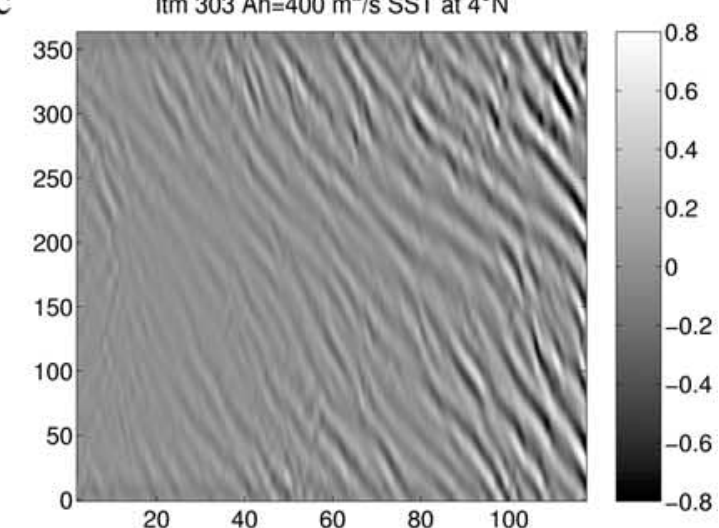

d

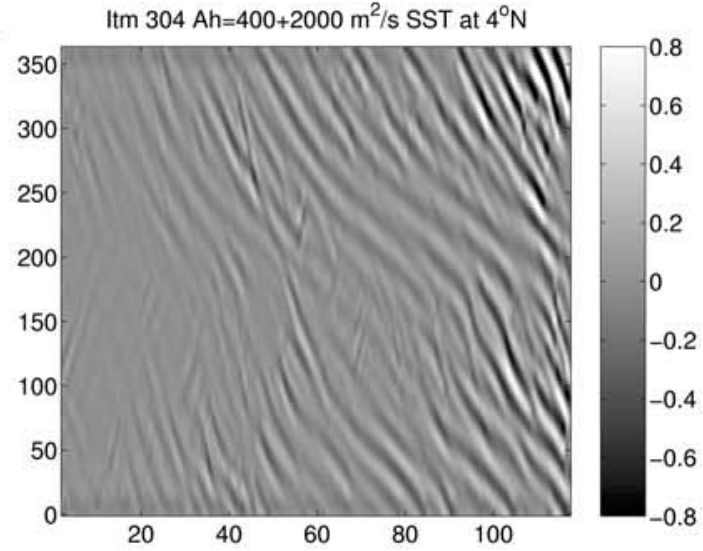

level of lateral mixing. Baroclinic conversion is strongest in the region where TIWs originate, just north (between $2^{\circ} \mathrm{N}$ and $\left.5^{\circ} \mathrm{N}\right)$ and south $\left(2^{\circ} \mathrm{S}\right.$ and $\left.5^{\circ} \mathrm{S}\right)$ of the equator. Note that the maximum value of the baroclinic conversion term is actually highest for $A_{h}=2.0 \times 10^{3} \mathrm{~m}^{2} \mathrm{~s}^{-1}$ (Figures $5 \mathrm{~d}$ and $6 \mathrm{~d})$. There is a strong interplay between the vertical and horizontal shear and the barotropic and baroclinic production of eddy kinetic energy.

[39] The pattern and strength of the barotropic and baroclinic conversion terms with $A_{h}=2.0 \times 10^{3} \mathrm{~m}^{2} \mathrm{~s}^{-1}$ are comparable to those found by Masina et al. [1999] in their experiments using a more realistic model domain and constant wind forcing. Here we find, however, that the production of eddy kinetic energy (particularly that brought about by barotropic instability) is very sensitive to the level and form of lateral mixing.

[40] The energy conversion terms are shown as a function of time and depth in Figure 7 . In each case, we have averaged the conversion term over the $90^{\circ}$ to $110^{\circ}$ longitudinal band and between $8^{\circ} \mathrm{S}$ and $8^{\circ} \mathrm{N}$. The general form of the baroclinic conversion term changes little as the lateral mixing is varied; it reaches a maximum around October with a secondary maximum around March. Both maxima are around $40 \mathrm{~m}$ depth. Decreasing the lateral mixing coefficient has a tendency to shift both maxima by about a month earlier in the year, with an increase in the secondary maximum, and a slight reduction in the depth for which the term is positive. Interestingly, the secondary maximum has its largest value for the enhanced mixing case.

[41] There are major changes to the barotropic conversion term. Again, the major activity is around $40 \mathrm{~m}$ depth. However, with $A_{h}=2.0 \times 10^{3} \mathrm{~m}^{2} \mathrm{~s}^{-1}$, the levels of the barotropic term are generally low, except toward the end of the year, with the barotropic term peaking after the baroclinic term. With $A_{h}=4.0 \times 10^{2} \mathrm{~m}^{2} \mathrm{~s}^{-1}$, there is enhanced barotropic activity from the middle of June onward, with a maximum before that of the baroclinic term, continuing through to April the next year, while for the enhanced mixing case the levels of barotropic activity are much reduced. The times with enhanced levels of baroclinic conversion correspond to times with high TIW activity. A more detailed analysis of the seasonality and spectral characteristics of the TIWs is done in the next section.

\section{Tropical Instability Waves}

[42] The manifestation of the mean to eddy conversions, and the resulting eddy kinetic energy, is primarily TIWs. In this section the characteristics of the model generated TIWs are examined as a function of the lateral mixing imposed in the model experiments. The model is able to capture the basic observed characteristics of TIW activity and their

Figure 8. (opposite) Filtered SST, displaying TIWs, at $4^{\circ} \mathrm{N}$ as a function of time (y-direction) and longitude (x-direction), for the fine model grid resolution experiments mixing tracers and momentum along isopycnal surfaces. (a) $A_{h}=4.0 \times 10^{3} \mathrm{~m}^{2} \mathrm{~s}^{-1}$, (b) $A_{h}=2.0 \times 10^{3} \mathrm{~m}^{2} \mathrm{~s}^{-1}$, (c) $A_{h}=$ $4.0 \times 10^{2} \mathrm{~m}^{2} \mathrm{~s}^{-1}$, and (d) enhanced lateral mixing (Add) experiment. Units are ${ }^{\circ} \mathrm{C}$. See color version of this figure at back of this issue. 


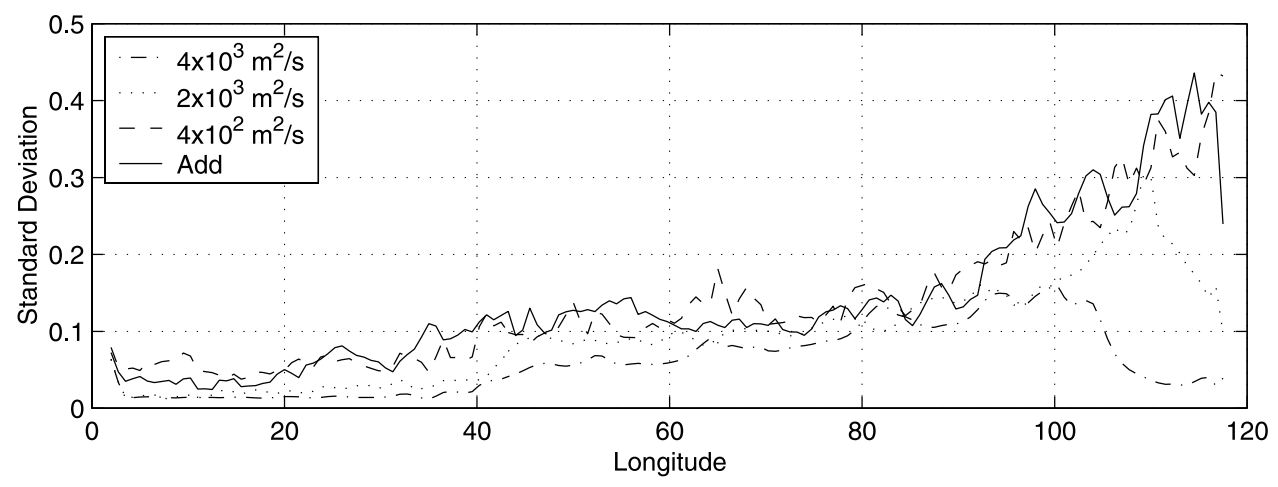

Figure 9. SST standard deviation at $4^{\circ} \mathrm{N}$ for the fine model grid resolution experiments mixing tracers and momentum along isopycnal surfaces. Dash-dotted line is the experiment using $A_{h}=4.0 \times 10^{3} \mathrm{~m}^{2} \mathrm{~s}^{-1}$, dotted line is $A_{h}=2.0 \times 10^{3} \mathrm{~m}^{2} \mathrm{~s}^{-1}$, dashed line is $A_{h}=4.0 \times 10^{2} \mathrm{~m}^{2} \mathrm{~s}^{-1}$, and solid line is the enhanced lateral mixing (Add) experiment. The units are ${ }^{\circ} \mathrm{C}$.

seasonality. The waves in the model experiments are present between $2^{\circ} \mathrm{N}-4^{\circ} \mathrm{N}$ and $2^{\circ} \mathrm{S}-4^{\circ} \mathrm{S}$ within the eastern part of the domain and exhibit a well defined cusp-shaped wave pattern (not shown), typically extending from $70^{\circ}$ to $120^{\circ}$ of longitude.

[43] Here we examine the model TIW activity using time series of SST at $4^{\circ} \mathrm{N}$ during the last year of integration. At this latitude the signal of the model TIW activity in SST is strongest because of the strong meridional gradient in SST. To isolate and enhance the signal of the westward propagating features (TIW), a high-pass 2-D digital filter is applied. The digital filter used takes into account wavelength and period (see Cipollini et al. [2001] for filter details). In our case, TIWs are considered to be all oscillations with zonal wavelength ranging from $5^{\circ}$ to $25^{\circ}$ of longitude and period ranging from 10 to 60 days.

[44] The resultant high-pass SST data are showed in Figure 8 as a Hovmöller (time-longitude) diagram for the fine grid resolution experiments when tracers and momentum are mixed along isopycnal surfaces. The TIW can be clearly identified in the time-longitude plots as westward propagating features whose amplitude is modulated on seasonal timescale, the most energetic period being the second half of the year and extending to the beginning of the following year. The properties of the TIWs are very sensitive, as is the mean state, to the level and orientation of the lateral mixing (Figure 8).

[45] Experiments using horizontal mixing for tracers and momentum tend to damp out the TIW activity (not shown) when compared with isopycnal mixing. Additionally, the waves are more intense and confined to the eastern part of the domain when both tracers and momentum are mixed along isopycnal surfaces. A large diffusivity tends to damp the wave activity, producing more organized propagation patterns as well as confining the most active waves to the eastern portion of the domain, as shown in Figure 8 (top left panel). The experiment with $A_{h}=4.0 \times 10^{3} \mathrm{~m}^{2} \mathrm{~s}^{-1}$ produces the waves with smallest intensity (see Figure 9), with a maximum value of the standard deviation of $0.16^{\circ} \mathrm{C}$, compared with the other experiments shown. As the mixing coefficient is decreased the waves become more energetic and their behavior more irregular in time. For example, consider the experiment with $A_{h}=4.0 \times 10^{2} \mathrm{~m}^{2} \mathrm{~s}^{-1}$ (Figure 8 , bottom left panel). The TIW variability is increased over the full width of the domain, compared to experiments with a higher diffusivity, with the standard deviation reaching a maximum of $0.43^{\circ} \mathrm{C}$ (see Table 2) in the eastern part of the domain. However, note that the experiment with enhanced equatorial mixing produces waves which are slightly more energetic, but more confined to the eastern part of the domain, compared with the waves produced with lower mixing. As mentioned in section 5, there are changes to the seasonality of the TIW as a function of the mixing scheme. With a lower lateral mixing coefficient, the TIWs tend to occur during the whole year as shown in Figure 8 (bottom left panel). However, TIWs in the case with enhanced equatorial mixing have a seasonal cycle similar to the experiment using $A_{h}=2.0 \times 10^{3} \mathrm{~m}^{2} \mathrm{~s}^{-1}$, displaying two periods in the year with large activity and one intermediate period in the middle of the year with less activity.

[46] In order to provide an objective estimate of the TIW propagation speed, we apply a 2-D radon transform (RT) to the high-pass data shown in Figure 8 (see Challenor et al. [2001] for an application of the 2-D radon transform to satellite oceanographic data). The RT gives the strength of the signal as a function "slope" or wave speed. The normalized RT power as a function of wave speed is shown in Figure 10. The wave speed which has the greatest power is given in Table 2 for each experiment. This wave speed is taken as the propagation speed, $c_{T}$, of the TIWs. The TIW propagation speed is highest, $c_{T}=29 \mathrm{~cm} \mathrm{~s}^{-1}$, for the case with the highest value of $A_{h}\left(4.0 \times 10^{3} \mathrm{~m}^{2} \mathrm{~s}^{-1}\right)$. For lower values of $A_{h}, c_{T}$ is approximately $24 \mathrm{~cm} \mathrm{~s}^{-1}$ (the differences between these three experiments are probably not signifi-

Table 2. Table Showing Diagnostic Statistics ${ }^{\mathrm{a}}$

\begin{tabular}{lccc}
\hline Name & $A_{h}$ & $S t d_{\max }$ & $c_{T}$ \\
\hline Itm301 & $4.0 \times 10^{3}$ & 0.16 & 29 \\
Itm302 & $2.0 \times 10^{3}$ & 0.30 & 23 \\
Itm303 & $4.0 \times 10^{2}$ & 0.43 & 24 \\
Itm304 & $4.0 \times 10^{2}+2.0 \times 10^{3}$ & 0.43 & 23 \\
\hline
\end{tabular}

${ }^{a}$ First column gives experiment names and second gives the lateral mixing coefficients used in the experiments (units are $\mathrm{m}^{2} \mathrm{~s}^{-1}$ ). Third column gives the maximum value of the standard deviation of temperature along $4^{\circ} \mathrm{N}$ (units are in ${ }^{\circ} \mathrm{C}$ ). Fourth column gives the maximum wave propagation speed $c_{T}$ obtained with radon transform (units are in $\mathrm{cm} \mathrm{s}^{-1}$ ). 


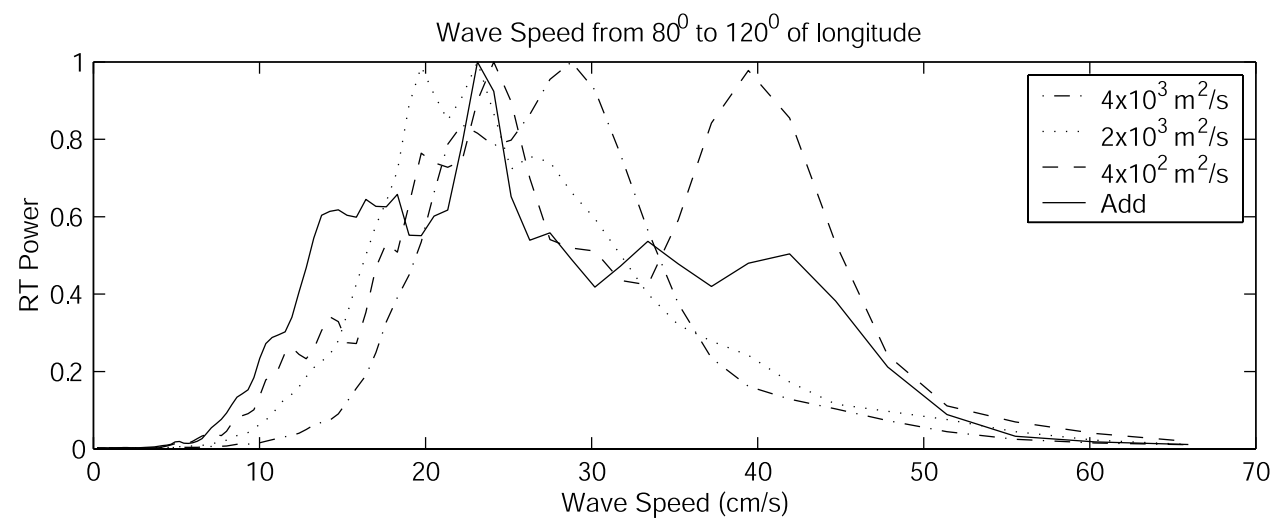

Figure 10. Wave speed obtained with the radon transform calculated from SST at $4^{\circ} \mathrm{N}$ for the fine model grid resolution experiments mixing tracers and momentum along isopycnal surfaces. Dash-dotted line is the experiment using $A_{h}=4.0 \times 10^{3} \mathrm{~m}^{2} \mathrm{~s}^{-1}$, dotted line is $A_{h}=2.0 \times 10^{3} \mathrm{~m}^{2} \mathrm{~s}^{-1}$, dashed line is $A_{h}=$ $4.0 \times 10^{2} \mathrm{~m}^{2} \mathrm{~s}^{-1}$, and solid line is the enhanced lateral mixing (Add) experiment. The units are $\mathrm{cm} \mathrm{s}^{-1}$.

cant). However, for the lowest value of $A_{h}(4.0 \times$ $\left.10^{2} \mathrm{~m}^{2} \mathrm{~s}^{-1}\right)$, there is a distinct secondary peak in the wave speed at around $40 \mathrm{~cm} \mathrm{~s}^{-1}$. The enhanced mixing case also has a secondary peak, but less distinct, around the same wave speed and also lower speed values $\left(20 \mathrm{~cm} \mathrm{~s}^{-1}\right)$. These slower moving waves are discernible in the time-longitude plots in the bottom panels of Figure 8. Similar waves can be seen in the top panels, but with an amplitude such that they do not show up in the RT analysis.

\section{Summary and Conclusions}

[47] The model equatorial current system is found to be very sensitive to the level and form of lateral mixing. Both the mean currents and wave activity become more energetic as the magnitude of the lateral mixing coefficient is decreased. As others have found, if the lateral mixing is oriented along isopycnic surfaces, then there is, in general, a speeding up of the current system and a better defined NECC. However, these differences are dependent on the grid and level of mixing. With the lowest value of the lateral mixing coefficient we consider, the results in terms of the strength of the EUC and the SST in the cold tongue region are less dependent on either the formulism of lateral mixing or the grid spacing (see Table 1 and Figure 2). This points to some sort of numerical convergence and independence of the way sub-grid scale (unresolved) processes are treated with modest grid resolution. However, it should be noted that there is a $30 \%$ increase in the EKE going from horizontal to isopycnic mixing (Table 1) with the lowest value of the lateral mixing coefficient we consider.

[48] A major conclusion from the results using a conventional constant value for the lateral mixing coefficient is that regardless of the level of mixing or its orientation, the model equatorial ocean cannot be made comparable to observations (with the caveat that we are considering an idealized geometry and forcing). Decreasing the mixing increases the cold tongue SST (which in general is good) but produces unrealistically strong currents (which is bad). Our solution to this dilemma is to invoke enhanced mixing close to the equator, which limits the strength of the EUC while little affecting the TIW activity and hence the cold tongue SST (see Figure 2). The physical rationale we put forward for this enhanced mixing is the effect of the observed interleaving of water masses in producing a meridional flux of tracers and momentum [Richards and Banks, 2002; Richards and Edwards, 2003].

[49] Experiments using horizontal mixing for tracers and momentum tend to damp out the TIW activity (not shown) when compared with isopycnal mixing. Additionally, the waves are more intense and confined to the eastern part of the domain when both tracers and momentum are mixed along isopycnic surfaces.

[50] Both the barotropic and baroclinic energy conversion terms are found to be important for the production of TIWs. The relative role of each and timing of these conversion terms changes as the level of imposed mixing changes. At low levels of lateral mixing, barotropic instability is found to dominate the production of total eddy energy. Including enhanced mixing at the equator reduces this barotropic production, but increases the baroclinic production away from the equator. As the mixing coefficient is decreased, the TIWs become more energetic and their behavior more irregular, with reduced seasonality. A large diffusivity tends to damp the wave activity, producing more organized propagation patterns with a stronger seasonality as well as confining the main activity of the waves to the eastern portion of the domain (Figure 8). These characteristics with a large diffusion coefficient are similar to those of observed TIWs [see, e.g., Vialard et al. [2001]. However, as before, with a small grid size it is inappropriate to apply such a large diffusion coefficient in the model unless there are physical reasons to do so, and we still need to retain the lateral heat transport associated with the wave activity. The implication is that we are still missing some important physics in modeling TIW activity.

[51] The sensitivity of the flow in the equatorial ocean to lateral mixing we have here means that the form and action of that mixing needs a careful examination. It is not the case that simply increasing a model's resolution will lead to better results if the physics of the model itself are deficient. Here we have identified interleaving as having a significant effect on both the mean properties of the ocean and the TIW activity. There may well be other processes. It is unlikely, in the near future, that ocean GCMs used in climate studies will have the required vertical resolution (order $1 \mathrm{~m}$ ) in 
order to properly resolve the interleaving. We therefore have to resort to parameterizing its effect. Here we have used a relatively crude parameterization. Richards and Edwards [2003] suggest that inertial instability is the prime mechanism for the formation of the interleaving. In this case, we expect the growth, and associated lateral fluxes of tracers and momentum, to be dependent on the lateral shear, and that the mixing is variable in both space and time. Our next step is to test the parameterization suggested by Richards and Edwards [2003] in an ocean GCM with more realistic geometry and forcing.

[52] Acknowledgments. We would like to thank the OPA development team at LODYC for providing the model source code (http:// www.lodyc.jussieu.fr/opa/index.html), Claire Lévy for assistance with the software, and Matthieu Lengaigne and Gurvan Madec for providing the isopycnal mixing routines. We would also like to thank Neil Edwards for help in configuring the model code and Paolo Cipollini for discussions about the digital filter. Thanks go to John Toole and an anonymous reviewer in providing helpful comments that have led to an improvement in the presentation of the results. This work was supported by the Conselho Nacional de Pesquisas - CNPq Brazil grant 200748/98-0. The IPRC is sponsored in part by the Frontier Research System for Global Change. This manuscript is SOEST contribution 6296 and IPRC contribution 248.

\section{References}

Banks, T. H., Intrusions and mixing in the western equatorial Pacific, Ph.D. thesis, Univ. of Southampton, Southampton, UK, 1996.

Blanke, B., and P. Delecluse, Variability of the tropical Atlantic Ocean simulated by a general circulation model with two different mixed layer physics, J. Phys. Oceanogr., 23, 1363-1388, 1993.

Bryan, K., A numerical method for the study of the circulation of the world ocean, J. Comp. Phys., 4, 347-376, 1969.

Challenor, P. G., P. Cipollini, and D. Cromwell, Use of the 3D radon transform to examine the properties of oceanic Rossby waves, J. Atmos. Oceanic Technol., 18, 1558-1566, 2001.

Chelton, D. B., F. J. Wentz, C. L. Gentemann, R. A. Szoeke, and M. G. Schlax, Satellite microwave SST observations of transequatorial tropical instability waves, Geophys. Res. Lett., 27(9), 1239-1242, 2000.

Cipollini, P., P. G. Cromwell, D. Challenor, and S. Raffaglio, Rossby waves detected in global ocean colour data, Geophys. Res. Lett., 28(2), 323326, 2001.

Delecluse, P., Modelling the ocean circulation, in Long-Term Climatic Variations: Data and Modelling, NATO ASI Ser. 1, vol. 22, edited by J. C. Duplessy and M. T. Spyridakis, pp. 73 -106, Springer-Verlag, New York, 1994.

Hastenrath, S., On meridional heat transports in the world ocean, J. Phys Oceanogr., 12, 922-927, 1982

Hellerman, S., and M. Rosenstein, Normal monthly wind stress over the world ocean with error estimates, J. Phys. Oceanogr., 13, 1093-1104, 1983.

Large, W. G., G. Danabasoglu, J. C. McWilliams, P. R. Gent, and F. O. Bryan, Equatorial circulation of a global ocean climate model with anisotropic horizontal viscosity, J. Phys. Oceanogr., 31, 518-536, 2001.
Legeckis, R., Long waves in the eastern equatorial Pacific Ocean: A view from a geostationary sattelite, Science, 197, 1179-1181, 1977.

Lengaigne, M., G. Madec, C. Menkes, A. Jouzeau, and G. Alory, Impact of isopycnal mixing on the tropical ocean circulation, J. Geophys. Res., 108(C11), 3345, doi:10.1029/2002JC001704, 2003.

Levitus, S., and T. Boyer, World Ocean Atlas 1994, vol. 3, Salinity, NOAA Atlas NESDIS 3, Natl. Oceanic and Atmos. Admin., Silver Spring, Md., 1994a.

Levitus, S., and T. Boyer, World Ocean Atlas 1994, vol. 4, Temperature, NOAA Atlas NESDIS 4, Natl. Oceanic and Atmos. Admin., Silver Spring, Md., 1994b.

Luther, D. S., and E. S. Johnson, Eddy energetics in the upper equatorial Pacific during Hawaii-to-Tahiti shuttle experiment, J. Phys. Oceanogr., 20, 913-944, 1990

Madec, G., P. Delecluse, M. Imbard, and C. Lvy, OPA8.1 Ocean General Circulation Model: Reference manual, Notes du Ple de Modl. 11, 93 pp., Lab. d'Ocanogr. Dyn. et de Climatol. (LOYDC), Paris, 1998.

Maes, C., G. Madec, and P. Delecluse, Sensitivity of an equatorial Pacific OGCM to the lateral diffusion, Mon. Weather Rev, 125, 958-971, 1997.

Masina, S., S. G. H. Philander, and A. B. G. Bush, An analysis of tropical instability waves in a numerical model of the Pacific Ocean: 2. Generation and energetics of the waves, J. Geophys. Res., 104(C12), 29,637$29,661,1999$.

Megann, A., and A. New, The effects of resolution and viscosity in an isopycnic-coordinate model of the equatorial Pacific, J. Phys. Oceanogr., 31, 1993-2018, 2001.

Neelin, J. D. A., Tropical air-sea interaction in general circulation models, Clim. Dyn., 7, 73-104, 1992.

Philander, S. G. H., El Niño, La Niña, and the Southern Oscillation, Academic, San Diego, Calif., 1990.

Qiao, L., and R. H. Weisberg, Tropical instability wave energetics: Observations from the Tropical Instability Wave Experiment, J. Phys. Oceanogr., 28, 345-360, 1998.

Richards, K. J., Interleaving at the equator, in Ocean Modelling and Parameterization, NATO Ser. C, vol. 516, pp. 235-252, Springer-Verlag, New York, 1998.

Richards, K. J., and H. Banks, Characteristics of interleaving in the western equatorial Pacific, J. Geophys. Res., 107(C12), 3231, doi:10.1029/ 2001JC000971, 2002.

Richards, K. J., and N. Edwards, Lateral mixing in the equatorial Pacific: The importance of inertial instability, Geophys. Res. Lett., 30(17), 1888, doi:10.1029/2003GL017768, 2003.

Stockdale, T. D., D. Anderson, M. Davey, P. Delecluse, A. Kattemberg, Y. Kitamura, M. Latif, and T. Yamagata, Intercomparison of tropical Pacific Ocean GCM's, WMO/TD-545, 43 pp., World Meteorol. Org., Geneva, 1993

Vialard, J., C. Menkes, J.-P. Boulanger, P. Delecluse, E. Guilyardi, and M. McPhaden, A model study of the oceanic mechanisms affecting the equatorial SST during the 1997-98 El Niño, J. Phys. Oceanogr., 31, 1649-1675, 2001.

L. P. Pezzi, Center for Weather Forecast and Climate Studies (CPTEC), National Institute for Space Research (INPE), Rodovia Presidente Dutra, Km 40, Cachoeira Paulista, SP, CEP 12260-000, Brazil. (luciano@cptec. inpe.br)

K. J. Richards, International Pacific Research Center/SOEST, University of Hawaii at Manoa, POST Building 409, 1680 East West Road, Honolulu, HI 96822, USA. (rkelvin@hawaii.edu) 
a

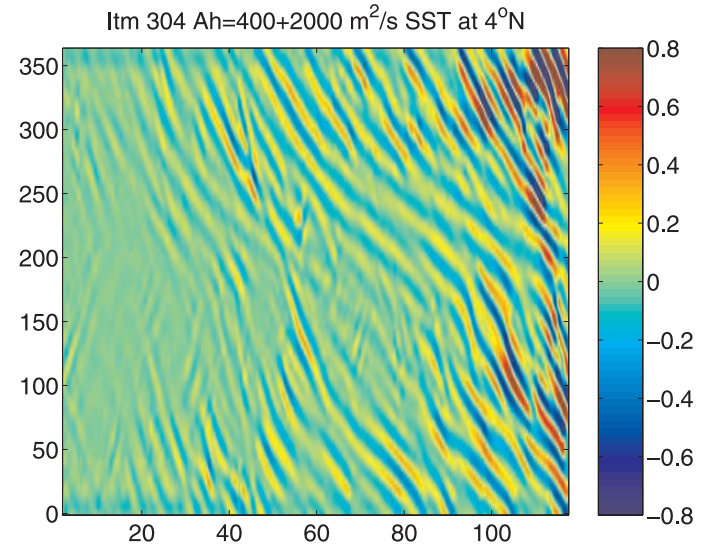

b

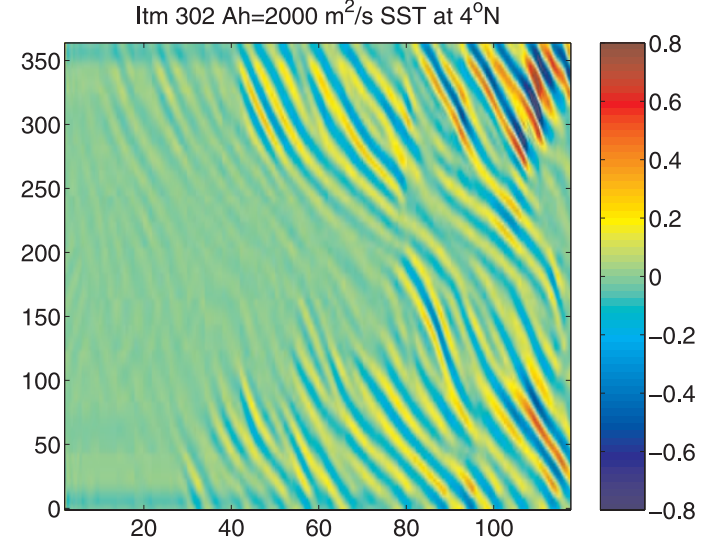

c

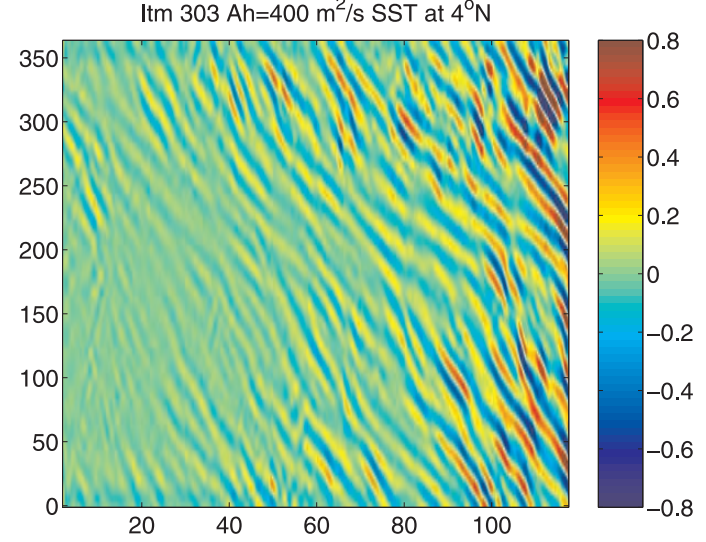

d Itm $304 \mathrm{Ah}=400+2000 \mathrm{~m}^{2} / \mathrm{s} \mathrm{SST}$ at $4^{\circ} \mathrm{N}$

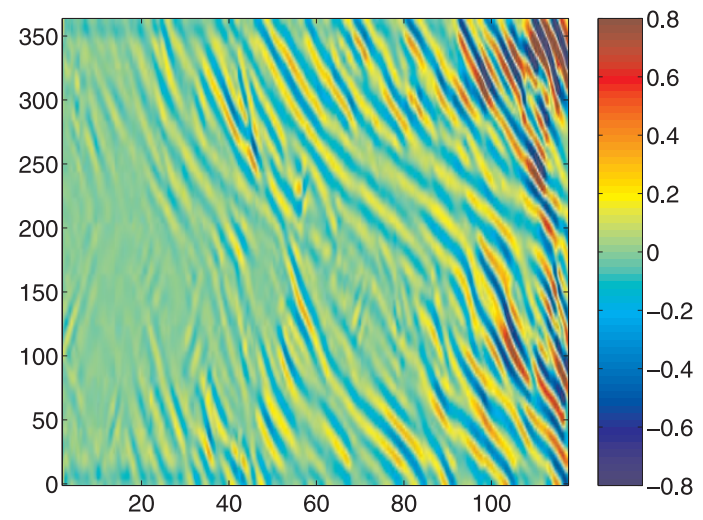

Figure 8. (opposite) Filtered SST, displaying TIWs, at $4^{\circ} \mathrm{N}$ as a function of time (y-direction) and longitude (x-direction), for the fine model grid resolution experiments mixing tracers and momentum along isopycnal surfaces. (a) $A_{h}=4.0 \times 10^{3} \mathrm{~m}^{2} \mathrm{~s}^{-1}$, (b) $A_{h}=2.0 \times 10^{3} \mathrm{~m}^{2} \mathrm{~s}^{-1}$, (c) $A_{h}=$ $4.0 \times 10^{2} \mathrm{~m}^{2} \mathrm{~s}^{-1}$, and (d) enhanced lateral mixing (Add) experiment. Units are ${ }^{\circ} \mathrm{C}$. 